Stefan Engelberg

\title{
2 Frameworks of lexical decomposition of verbs
}

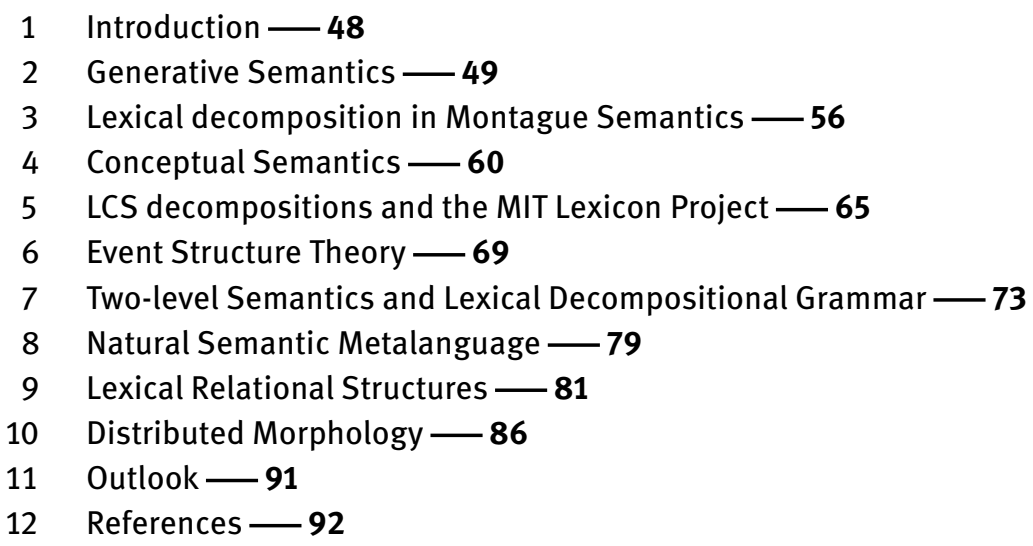

Abstract: Starting from early approaches within Generative Grammar in the late 1960s, the article describes and discusses the development of different theoretical frameworks of lexical decomposition of verbs. It presents the major subsequent conceptions of lexical decompositions, namely, Dowty's approach to lexical decomposition within Montague Semantics, Jackendoff's Conceptual Semantics, the LCS decompositions emerging from the MIT Lexicon Project, Pustejovsky's Event Structure Theory, Wierzbicka's Natural Semantic Metalanguage, Wunderlich's Lexical Decompositional Grammar, Hale and Kayser's Lexical Relational Structures, and Distributed Morphology. For each of these approaches, (i) it sketches their origins and motivation, (ii) it describes the general structure of decompositions and their location within the theory, (iii) it explores their explanative value for major phenomena of verb semantics and syntax, (iv) and it briefly evaluates the impact of the theory. Referring to discussions in article 7 [Semantics: Foundations, History and Methods] (Engelberg) Lexical decomposition, a number of theoretical topics are taken up throughout the paper concerning the interpretation of decompositions, the basic inventory of decompositional predicates, the location of decompositions on the different levels of linguistic representation (syntactic, semantic, conceptual), and the role they play for the interfaces between these levels. 


\section{Introduction}

The idea that word meanings are complex has been present ever since people have tried to explain and define the meaning of words. When asked the meaning of the verb persuade, a competent speaker of the language would probably say something like (1a). This is not far from what semanticists put into a structured lexical decomposition as in (1b):

(1) a. You persuade somebody if you make somebody believe or do something.

b. persuade( $\mathrm{x}, \mathrm{y}, \mathrm{z})$ : $\mathrm{x}$ CAUSE (y BELIEVE $\mathrm{z}$ )

(after Fillmore 1968a: 377)

However, it was not until the mid-1960s that intuitions about the complexity of verb meanings lead to formal theories of their lexical decomposition. This article will review the history of lexical decomposition of verbs from that time on. For some general discussion of the concept of decomposition and earlier decompositional approaches, cf. article 7 [Semantics: Foundations, History and Methods] (Engelberg) Lexical decomposition. The first theoretical framework to systematically develop decompositional representations of verb meanings was Generative Semantics (section 2), where decompositions were representations of syntactic deep structure. Later theories did not locate lexical decompositions on a syntactic level but employed them as representations on a lexical-semantic level as in Dowty's Montague-based approach (section 3) and the decompositional approaches emerging from the MIT Lexicon Project (section 5) or on a conceptual level as in Jackendoff's Conceptual Semantics (section 4). Other lexical approaches were characterized by the integration of decompositions into an Event Structure Theory (section 6), the conception of a comprehensive Natural Semantic Metalanguage (section 7), and the development of a systematic structure-based linking mechanism as in Lexical Decomposition Grammar (section 8). Parallel to these developments, new syntactic approaches to decompositions emerged such as Hale and Kayser's Lexical Relational Structures (section 9) and Distributed Morphology (section 10).

Throughout the paper a number of theoretical topics will be touched upon that are discussed in more detail in article 7 [Semantics: Foundations, History and Methods] (Engelberg) Lexical decomposition. Of particular interest will be the questions on which level of linguistic representation (syntactic, semantic, conceptual) decompositions are located, how the interfaces to other levels of linguistic representation are designed, what evidence for the complexity of word meaning is assumed, how decompositions are semantically interpreted, what role the formal structure of decompositions plays in explanations of linguistic phenomena, and what the basic inventory of decompositional predicates is.

In the following sections, the major theoretical approaches involving lexical decompositions will be presented. Each approach will be described in four 
subsections that (i) sketch the historical development that led to the theory under discussion, (ii) describe the place lexical decompositions take in these theories and their structural characteristics, (iii) present the phenomena that are explained on the basis of decompositions, and (iv) give a short evaluation of the impact of the theory.

\section{Generative Semantics}

\subsection{Origins and motivation}

Generative Semantics was a school of syntactic and semantic research that opposed certain established views within the community of Generative Grammar. It was active from the mid-1960s through the mid-1970s. Its major proponents were George Lakoff, James D. McCawley, Paul M. Postal, and John Robert Ross. (For the history of Generative Semantics, cf. Binnick 1972; McCawley 1994.)

At that time, the majority view held within Generative Grammar was that there is a single, basic structural level on which generative rules operate and to which all other structural levels are related by interpretive rules. This particular structural level was syntactic deep structure from which semantic interpretations were derived. It was this view of 'interpretive semantics' that was not shared by the proponents of Generative Semantics.

Although there never was a "standard theory" of Generative Semantics, a number of assumptions can be identified that were wide-spread in the GScommunity (cf. Lakoff 1970; McCawley 1968; Binnick 1972): (i) Deep structures are more abstract than Chomsky (1965) assumed. In particular, they are semantic representations of sentences. (ii) Syntactic and semantic representations have the same formal status: They are structured trees. (iii) There is one system of rules that relates semantic representations and surface structures via intermediary representations.

Some more specific assumptions that are important when it comes to lexical decomposition were the following: (iv) In semantic deep structure, lexical items occur as decompositions where the semantic elements of the decomposition are distributed over the structured tree (cf. e.g., Lakoff 1970; McCawley 1968; Postal 1971). (v) Some transformations take place before lexical insertion (prelexical transformations, McCawley 1968). (vi) Semantic deep structure allows only three categories: V (corresponding to predicates), NP (corresponding to arguments), and $\mathrm{S}$ (corresponding to propositions). Thus, for example, verbs, adjectives, quantifiers, negation, etc. are all assigned the category $\mathrm{V}$ in semantic deep structure 
(cf. Lakoff 1970: 115ff; Bach 1968; Postal 1971). (vii) Transformations can change syntactic relations: Since Floyd broke the glass contains a structure expressing the glass broke as part of its semantic deep structure, the glass occurs as subject in semantic deep structure and as object in surface structure.

\subsection{Structure and location of decompositions}

In Generative Semantics, syntactic and semantic structures do not constitute different levels or modules of linguistic theory. They are related by syntactically motivated transformations; that is, although semantic by nature, the lexical decompositions occurring in semantic deep structure and intermediate levels of sentence derivation must be considered as parts of syntactic structure.

In contrast to the "Aspects"-model of Generative Syntax (Chomsky 1965), the terminal constituents of semantic deep structure are semantic and not morphological entities. Particularly interesting for the development of theories of lexical decomposition is the fact that semantic deep structure contained abstract verbs like CAUSE or CHANGE (Fig. 2.1) that were sublexical in the sense that they were part of a lexical decomposition. Moreover, it was assumed that all predicates that appear in semantic deep structure are abstract predicates. A basic abstract predicate like BELIEVE resembles the actual word believe in its meaning and its argument-taking properties, but unlike actual words, it is considered to be unambiguous. These abstract entities attach to the terminal nodes in semantic deep structure (cf. Fig. 2.1 and for structures and derivations of this sort Lakoff 1965; McCawley 1968; Binnick 1972).

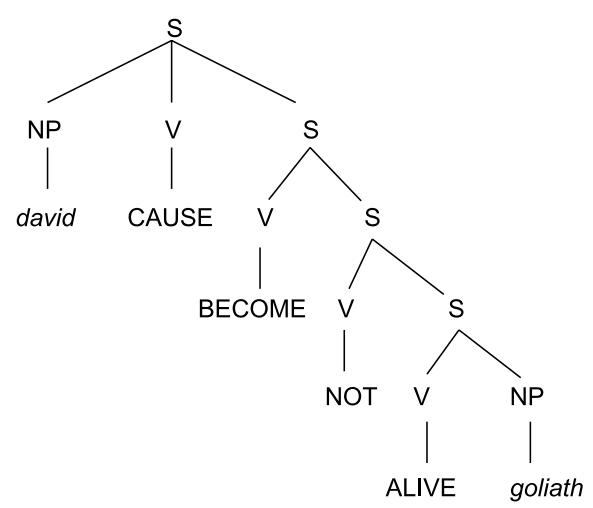

Fig. 2.1: Semantic deep structure for David killed Goliath

Abstract predicates can be moved by a transformation called 'predicate raising', a form of Chomsky adjunction that has the effect of fusing abstract predicates into predicate complexes (cf. Fig. 2.2). 


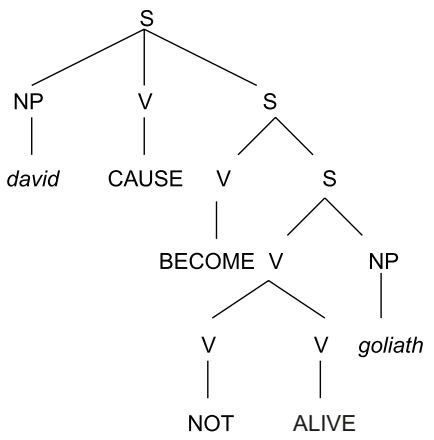

Fig. 2.2: Adjunction of ALIVE to NOT by predicate raising

Performing a series of transformations of predicate raising, the tree in Fig. 2.2 is transformed into the tree in Fig. 2.4 via the tree in Fig. 2.3.
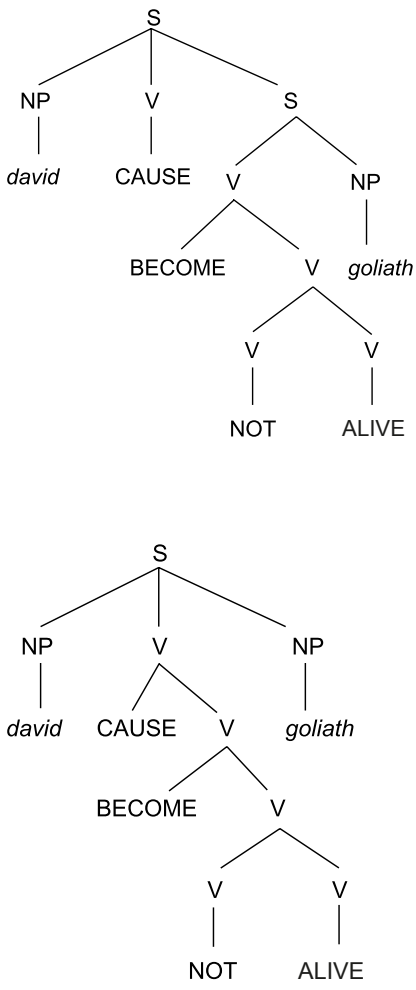

Fig. 2.3: Adjunction of NOT ALIVE to BECOME by predicate raising

Fig. 2.4: Adjunction of BECOME NOT ALIVE to CAUSE by predicate raising

Finally, the complex of abstract predicates gets replaced by a lexical item. The lexical insertion transformation '[CAUSE[весоме[NoT[ALIVE]]]] $\rightarrow$ kill' yields the tree in Fig. 2.5. 


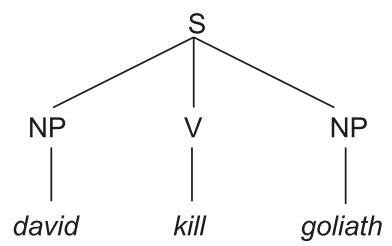

Fig. 2.5: Lexical insertion of kill, replacing [ CAUSE [ BECOME [ NOT ALIVE ] ] ]

According to McCawley (1968), predicate raising is optional. If it does not take place, the basic semantic components do not fuse. Thus, kill is only one option of expressing the semantic deep structure in Fig. 2.1 besides cause to die, cause to become dead, cause to become not alive, etc.

\subsection{Linguistic phenomena}

Since Generative Semantics considered itself a general theory of syntax and semantics, a large array of phenomena were examined within this school, in particular quantification, auxiliaries, tense, speech acts, etc. (cf. Immler 1974; McCawley 1994; Binnick 1972). In the following, a number of phenomena will be illustrated whose explanation is closely related to lexical decomposition.

(i) Possible words: Predicate raising operates locally. A predicate can only be adjoined to an adjacent higher predicate. For a sentence like (2a), Ross (1972: 109ff) assumes the semantic deep structure in (2b). The local nature of predicate raising predicts that the decompositional structure can be realized as try to find or in case of adjunction of FIND to TRY as look for. A verb conveying the meaning of 'try-entertain', on the other hand, is universally prohibited since ENTERTAIN cannot adjoin to TRY.

(2) a. Fritz looked for entertainment.

b. [TRY fritz [FIND fritz [ENTERTAIN someone fritz]]]

(ii) Lexical gaps: Languages have lexical gaps in the sense that not all abstract predicate complexes can be replaced by a lexical item. For example, while the three admitted structures CAUSE BECOME RED (redden), BECOME RED (redden), and RED (red) can be replaced by lexical items, the corresponding structures for blue show accidental gaps: CAUSE BECOME BLUE (no lexical item), BECOME BLUE (no lexical item), and BLUE (blue) (cf. McCawley 1968). Lexical items missing in English may exist in other languages, for example, French bleuir. Since the transformation of predicate raising is restricted in the way described above, Generative Semantics can distinguish between those non-existing lexical items that are ruled out in principle, namely, 
by the restrictions on predicate raising and those that are just accidentally missing.

(iii) Related sentences: Lexical decompositions allow us to capture identical sentence-internal relations across a number of related sentences. The relation between Goliath and NOT ALIVE in the three sentences David kills Goliath (cf. Fig. 2.1), Goliath dies, and Goliath is dead is captured by assigning an identical subtree expressing this relation to the semantic deep structures of all three sentences. Lakoff (1970: 33ff) provides an analysis of the adjective thick, the intransitive verb thicken, and the transitive verb thicken that systematically bridges the syntactic differences between the three items by exploring their semantic relatedness through decompositions.

(iv) Cross-categorical transfer of polysemy: The fact that the liquid cooled has two readings ('the liquid became cool' and 'the liquid became cooler') is explained by inserting into the decomposition the adjective from which the verb is derived where the adjective can assume the positive or the comparative form (Lakoff 1970).

(v) Selectional restrictions (cf. e.g., Postal 1971: 204ff): Generative Semantics is capable of stating generalizations over selectional restrictions. The fact that the object of kill and the subjects of die and dead share their selectional restrictions is due to the fact that all three contain the abstract predicate NOT ALIVE in their decomposition (cf. Postal 1971: 204ff).

(vi) Derivational morphology: Terminal nodes in lexical decompositions can be associated with derivational morphemes. McCawley (1968) suggests a treatment of lexical causatives like redden in which the causative morpheme en is inserted under the node вЕсомE in the decomposition CAUSE BECOME RED.

(vii) Reference of pronouns: Particular properties of the reference of pronouns are explained by relating pronouns to subtrees within lexical decompositions.

(3) a. Floyd melted the glass though it surprised me that he would do so.

b. Floyd melted the glass though it surprised me that it would do so.

In (3b) in contrast to (3a), the pronoun picks up the decompositional subtree the-glass BECOME MELTED within the semantic structure [Floyd CAUSE [theglass BECOME MELTED]] (cf. Lakoff 1970; Lakoff \& Ross 1972).

(viii) Semantics of adverbials: Adverbials often show scopal ambiguities (cf. Morgan 1969). Sentences like Rebecca almost killed Jamaal can have several readings depending on the scope of almost (cf. article 7 [Semantics: 
Foundations, History and Methods] (Engelberg) Lexical decomposition, section 1.2). Assuming the semantic deep structure [Do [Rebecca CAUSE [BECOME [Jamaal NOT ALIVE]]]], the three readings can be represented by attaching the adverb above to either DO, CAUSE, or NOT ALIVE. Similar analyses have been proposed for adverbs like again (Morgan 1969), temporal adverbials (cf. McCawley 1971), and durative adverbials like for four years in the sheriff of Nottingham jailed Robin Hood for four years, where the adverbial only modifies the resultative substructure indicating that Robin Hood was in jail (Binnick 1968).

\subsection{Evaluation}

Generative Semantics has considerably widened the domain of phenomena that syntactic and semantic theories have to account for. It stimulated research not only in syntax but particularly in lexical semantics, where structures similar to the lexical decompositions proposed by Generative Semantics are still being used. Yet, Generative Semantics experienced quite vigorous opposition, in particular from formal semantics, psycholinguistics, and, of course, proponents of interpretive semantics within Generative Grammar (e.g., Chomsky 1970). Some of the critical points pertaining to decompositions were the following:

(i) Generative Semantics was criticized for its semantic representations not conforming to standards of formal semantic theories. According to Bartsch \& Vennemann (1972: 10ff), the semantic representations of Generative Semantics are not logical forms: The formation rules for semantic deep structures are uninterpreted; operations like argument deletion lead to representations that are not well-formed; and the treatment of quantifiers, negation, and some adverbials as predicates instead of operators is inadequate. Dowty (1972) emphasizes that Generative Semantics lacks a theory of reference.

(ii) While the rules defining deep structure and the number of categories were considerably reduced by Generative Semantics, the analyses were very complex, and semantic deep structure differed extremely from surface structure (Binnick 1972: 14).

(iii) It was never even approximately established how many and what transformations would be necessary to account for all sentential structures of a language (Immler 1974: 121).

(iv) It often remained unclear how the reduction to more primitive predicates should proceed, that is, what criteria allow one to decide whether dead is decomposed as NOT ALIVE or alive as NOT DEAD (Bartsch \& Vennemann 1972: 22) - an objection that also applies to most other approaches to decompositions. 
(v) In most cases, a lexical item is not completely equivalent to its decomposition. De Rijk has shown that while forget and its presumed decomposition 'cease to know' are alike with respect to presuppositions, there are cases where argument-taking properties and pragmatic behaviour are not interchangeable. If somebody has friends in Chicago who suddenly move to Australia, it is appropriate to say I have ceased to know where to turn for help in Chicago but not I have forgotten where to turn for help in Chicago (de Rijk, after Morgan 1969: 57ff). More arguments of this sort can be found in Fodor's (1970) famous article Three Reasons for Not Deriving "Kill” from "Cause to Die” which McCawley (1994) could partly repudiate by reference to pragmatic principles.

(vi) A lot of the phenomena that Generative Semantics tried to explain by regular transformations on a decomposed semantic structure exhibited lexical idiosyncrasies and were less regular than would be expected under a syntactic approach. Here are some examples. Pronouns are sometimes able to refer to substructures in decompositions. Unlike example (3) above, in sentences with to kill, they cannot pick up the corresponding substructure $x$ BECOME DEAD (Fodor 1970: 429ff); monomorphemic lexical items often seem to be anaphoric islands:

(4) a. John killed Mary and it surprised me that he did so.

b. John killed Mary and it surprised me *that she did so.

While to cool shows an ambiguity related to the positive and the comparative form of the adjective (cf. section 2.3), to open only relates to the positive form of the adjective (Immler 1974: 143f). Sometimes selectional restrictions carry over to related sentences displaying the same decompositional substructure, in other cases they do not. While the child grew is possible, a decompositionally related structure does not allow child as the corresponding argument of grow: *the parents grew the child (Kandiah 1968). Adverbials give rise to structurally ambiguous sentence meanings, but they usually cannot attach to all predicates in a decomposition (Shibatani 1976: 11; Fodor et al. 1980: 286ff). In particular, Dowty (1979) showed that Generative Semantics overpredicted adverbial scope, quantifier scope, and syntactic interactions with cyclic transformations. He concluded that rules of semantic interpretation of lexical items are different from syntactic transformations (Dowty 1979: 284).

(vii) Furthermore, Generative Semantics was confronted with arguments derived from psycholinguistic evidence (cf. article 7 [Semantics: Foundations, History and Methods] (Engelberg) Lexical decomposition, section 3.6). 


\section{Lexical decomposition in Montague Semantics}

\subsection{Origins and motivation}

The interesting phenomena that emerged from the work of Generative Semanticists, on the one hand, and the criticism of the syntactic treatment of decompositional structures, on the other, led to new approaches to word-internal semantic structure. Dowty's $(1972 ; 1976 ; 1979)$ goal was to combine the methods and results of Generative Semantics with Montague's (1973) rigorously formalized framework of syntax and semantics where truth and denotation with respect to a model were considered the central notions of semantics.

Dowty refuted the view that all interesting semantic problems only concern the so-called logical words and compositional semantics. Instead, he assumed that compositional semantics crucially depends on an adequate approach to lexical meaning. While he acknowledged the value of lexical decompositions in that, he considered decompositions as incomplete unless they come with "an account of what meanings really are." Dowty (1979: v, 21) believed that the essential features of Generative Semantics can all be accommodated within Montague Semantics where the logical structures of Generative Semantics will get a model-theoretic interpretation and the weaknesses of the syntactic approaches, in particular overgeneration, can be overcome. In Montague Semantics, sentences are not interpreted directly but are first translated into expressions of intensional logic. These translations are considered the semantic representations that correspond to the logical structure (i.e., the semantic deep structure) of Generative Semantics (Dowty 1979: 22). Two differences between Dowty's approach and classical Generative Semantics have to be noted: Firstly, directionality is inverse. While Generative Semantics maps semantic structures onto syntactic surface structure, syntactic structures are mapped onto semantic representations in Dowty's theory. Secondly, in Generative Semantics but not in Dowty's theory, derivations can have multiple stages (Dowty 1979: 24ff).

\subsection{Structure and location of decompositions}

Lexical decompositions are used in Dowty (1979) mainly in order to reveal the different logical structures of verbs belonging to the several so-called Vendler classes. Vendler (1957) classified verbs (and verb phrases) into states, activities, accomplishments, and achievements according to their behaviour with respect to the progressive aspect and temporal-aspectual adverbials (cf. also article 9 
[Semantics: Noun Phrases and Verb Phrases] (Filip) Aspectual class and Aktionsart). Dowty (1979: 52ff) extends the list of phenomena associated with these classes, relates verbs of different classes to decompositional representations as in (5a-c), and also distinguishes further subtypes of these classes as in (5d-f) (cf. Dowty 1979: 123ff).

(5) a. simple statives

$\pi_{n}\left(a_{1}, \ldots, a_{n}\right)$

John knows the answer.

b. simple activities

$\operatorname{Do}\left(\alpha_{1},\left[\pi_{n}\left(\alpha_{1}, \ldots, \alpha_{n}\right)\right]\right)$

John is walking.

c. simple achievements

$\operatorname{BECOME}\left[\pi_{\mathrm{n}}\left(\alpha_{1}, \ldots, \alpha_{\mathrm{n}}\right)\right]$

John discovered the solution.

d. non-intentional agentive accomplishments

$\left[\left[\operatorname{Do}\left(\alpha_{1},\left[\pi_{\mathrm{n}}\left(\alpha_{1}, \ldots, \alpha_{\mathrm{n}}\right)\right]\right)\right]\right.$ CAUSE $\left.\left[\operatorname{BECOME}\left[\rho_{\mathrm{m}}\left(\beta_{1}, \ldots, \beta_{\mathrm{m}}\right)\right]\right]\right]$

John broke the window.

e. agentive accomplishments with secondary agent

$\left[\left[\operatorname{Do}\left(\alpha_{1},\left[\pi_{n}\left(\alpha_{1}, \ldots, \alpha_{n}\right)\right]\right)\right]\right.$ CAUSE $\left.\left[\operatorname{Do}\left(\beta_{1},\left[\rho_{m}\left(\beta_{1}, \ldots, \beta_{m}\right)\right]\right)\right]\right]$

John forced Bill to speak.

f. intentional agentive accomplishments

$\operatorname{DO}\left(\alpha_{1},\left[\operatorname{DO}\left(\alpha_{1}, \pi_{n}\left(\alpha_{1}, \ldots, \alpha_{n}\right)\right)\right.\right.$ CAUSE $\left.\left.\phi\right]\right)$

John murdered Bill.

The different classes are built up out of stative predicates $\left(\pi_{n}, \rho_{m}\right)$ and a small set of operators (DO, BECOME, CAUSE). Within an aspect calculus, the operators involved in the decompositions are given model-theoretic interpretations, and the stative predicates are treated as predicate constants. The interpretation of BECOME (6a) is based on von Wright's (1963) logic of change; the semantics of CAUSE (6b) as a bisentential operator (cf. Dowty 1972) is mainly derived from Lewis' (1973) counterfactual analysis of causality, and the less formalized analysis of Do (6c) relates to considerations about will and intentionality in Ross (1972).

(6) a. [весоме $\phi]$ is true at $I$ if there is an interval $J$ containing the initial bound of $I$ such that $\neg \phi$ is true at $J$ and there is an interval $K$ containing the final bound of $I$ such that $\phi$ is true at $K$ (Dowty 1979: 140). 
b. [ $\phi$ cause $\psi]$ is true if and only if (i) $\phi$ is a causal factor for $\psi$, and (ii) for all other $\phi^{\prime}$ such that $\phi^{\prime}$ is also a causal factor for $\psi$, some $\neg \phi$-world is as similar or more similar to the actual world than any $\neg \phi^{\prime}$-world is. $\phi$ is a causal factor for $\psi$ if and only if there is a series of sentences $\phi, \phi_{1}, \ldots$, $\phi_{\mathrm{n}}, \psi($ for $\mathrm{n} \geq 0$ ) such that each member of the series depends causally on the previous member.

$\phi$ depends causally on $\psi$ if and only if $\phi, \psi$ and $\neg \phi \square \rightarrow \neg \psi$ are all true (Dowty 1979: 108f).

c. $\square[\mathrm{DO}(\alpha, \phi) \leftrightarrow \phi \wedge$ UNDER_THE_UNMEDIATED_CONTROL_OF_THE_AGENT_ $\alpha(\phi)]$

(Dowty 1979: 118)

By integrating lexical decompositions into Montague Semantics, Dowty wants to expand the treatment of the class of entailments that hold between English sentences (Dowty 1979: 31); he aims to show how logical words interact with non-logical words (e.g., words from the domain of tense, aspect, and mood with Vendler classes), and he expects that lexical decompositions help to narrow down the range of possible lexical meanings (Dowty 1979: 34f, 125ff).

With respect to the semantic status of lexical decompositions, Dowty (1976: 209ff) explores two options; namely, that the lexical expression itself is decomposed into a complex predicate, or that it is related to a predicate constant via a meaning postulate (cf. article 7 [Semantics: Foundations, History and Methods] (Engelberg) Lexical decomposition, section 3.1). While he mentions cases where a strong equivalence between predicate and decomposition provides evidence for the first option, he also acknowledges that the second option might often be empirically more adequate since it allows the weakening of the relation between predicate and decomposition from a biconditional to a conditional. This would account for the observation that the complex phrase cause to die has a wider extension than kill.

\subsection{Linguistic phenomena}

Dowty provides explanations for a wide range of phenomena related to Vendler classes. A few examples are the influence of mass nouns and indefinites on the membership of expressions in Vendler classes (Dowty 1979: 78ff), the interaction of derivational morphology with sublexical structures of meaning (Dowty 1979: 32, 206f, 256ff), explanations of adverbial and quantifier scope (Dowty 1976: 213ff), the imperfective paradox (Dowty 1979: 133), the progressive aspect (Dowty 1979: 145ff), resultative constructions (Dowty 1979: 219ff), and temporalaspectual adverbials (for an hour, in an hour) (Dowty 1979: 332ff). 
Dowty also addresses aspectual composition. Since he conceives of Vendler classes in terms of lexical decomposition, he shows that decompositional structures involving CAUSE, BECOME, and DO are not only introduced via semantically complex verbs but also via syntactic and morphological processes. For example, accomplishments that arise when verbs are combined with prepositional phrases get their BECOME operator from the preposition (7a) where the preposition itself can undergo a process that adds an additional CAUSE component (7b) (Dowty 1979: 211f). In (7c), the morphological process forming deadjectival inchoatives is associated with a BECOME proposition (Dowty 1979: 206) that can be expanded with a CAUSE operator in the case of deadjectival causatives (Dowty 1979: 307f).

(7) a. John walks to Chicago. walk'(john) ^ BECOME be-at'(john, chicago)

b. John pushes a rock to the fence. $\exists \mathrm{x}\left[\operatorname{rock}^{\prime}(\mathrm{x}) \wedge \exists \mathrm{y}\left[\forall \mathrm{z}\left[\right.\right.\right.$ fence $\left.^{\prime}(\mathrm{z}) \Leftrightarrow \mathrm{y}=\mathrm{z}\right] \wedge$ push $^{\prime}($ john, $\mathrm{x})$ CAUSE BECOME beat ${ }^{\prime}$ $(\mathrm{x}, \mathrm{y})]]$

c. The soup cooled.

$\exists \mathrm{x}\left[\forall \mathrm{y}\left[\operatorname{soup}^{\prime}(\mathrm{y}) \Leftrightarrow \mathrm{x}=\mathrm{y}\right] \wedge \mathrm{BECOME} \operatorname{cool}^{\prime}(\mathrm{x})\right]$

\subsection{Evaluation}

Of the pre-80s work on lexical decomposition, besides the work of Jackendoff (cf. 2.4), it is probably Dowty's "Word Meaning and Montague Grammar" that still exerts the most influence on semantic studies. It has initiated a long period of research dominated by approaches that located lexical decompositions in lexical semantics instead of syntax. It must be considered a major advancement that Dowty was committed to providing formal truth-conditions for operators involved in decompositions. Many of the approaches preceding and following Dowty (1979) lack this degree of explicitness. His account of the compositional nature of many accomplishments, the interaction of aspectual adverbials with Vendler classes, and many other phenomena mentioned in section 3.3 served as a basis for discussion for the approaches to follow. Among the approaches particularly influenced by Dowty (1979) are van Valin's (1993) decompositions within Role and Reference Grammar, Levin and Rappaport Hovav's Lexical Conceptual Structures (cf. section 5), and Pustejovsky's Event Structures (cf. section 6). 


\section{Conceptual Semantics}

\subsection{Origins and motivation}

Along with lexical decompositions in Generative Semantics, another line of research emerged where semantic arguments of predicates were associated with the roles they played in the events denoted by verbs (Gruber 1965; Fillmore 1968b). Thematic roles like agent, patient, goal, etc. were used to explain how semantic arguments are mapped onto syntactic structures (cf. also article 3 [this volume] (Davis) Thematic roles). Early approaches to thematic roles assumed that there is a small set of unanalyzable roles that are semantically stable across the verbal lexicon. Thematic role approaches were confronted with a number of problems concerning the often vague semantic content of roles, their coarse-grained nature as a descriptive tool, the lack of reliable diagnostics for them, and the empirically inadequate syntactic generalizations (cf. the overview in Levin \& Rappaport Hovav 2005: 35ff; Dowty 1991: 553ff). As a consequence, thematic role theories developed in different ways by decomposing thematic roles into features (Rozwadowska 1988), by reducing thematic roles to just two generalized macroroles (van Valin 1993) or to proto-roles within a prototype approach based on lexical entailments (Dowty 1991), by combining them with event structure representations (Grimshaw 1990; Reinhart 2002), and, in particular, by conceiving of them as notions derived from lexical decompositions (van Valin 1993). This last approach was pursued by Jackendoff $(1972 ; 1976)$ and was one of the foundations of a semantic theory that came to be known as Conceptual Semantics, and which, over the years, has approached a large variety of phenomena beyond thematic roles (cf. also article 4 [Semantics: Theories] (Jackendoff) Conceptual Semantics).

According to Jackendoff's (1983; 1990; 2002) Conceptual Semantics, meanings are essentially conceptual entities and semantics is "the organization of those thoughts that language can express" (Jackendoff 2002: 123). Meanings are represented on an autonomous level of cognitive representation called "conceptual structure" that is related to syntactic and phonological structure, on the one side, and to non-linguistic cognitive levels like the visual, the auditory, and the motor system, on the other side. Conceptual structure is conceived of as a universal model of the mind's construal of the world (Jackendoff 1983: 18ff). Thus, Conceptual Semantics differs from formal, model-theoretic semantics in locating meanings not in the world but in the mind of speakers and hearers. Therefore, notions like truth and reference do not play the role they play in formal semantics but are relativized to the speaker's conceptualizations of the world (cf. Jackendoff 2002: 294ff). Jackendoff's approach also differs from many others in not assuming 
a strict division between semantic and encyclopaedic meaning and between grammatically relevant and irrelevant aspects of meaning (Jackendoff 2002: 267ff).

\subsection{Structure and location of decompositions}

Conceptual structure involves a decomposition of meaning into conceptual primitives (Jackendoff 1983: 57ff). Since Jackendoff (1990: 10f) assumes that there is an indefinitely large number of possible lexical concepts, conceptual primitives must be combined by generative principles to determine the set of lexical concepts. Thus, most lexical concepts are considered to be conceptually complex. Decompositions in Conceptual Semantics differ considerably in content and structure from lexical structure in Generative Semantics and Montague-based approaches to the lexicon. The sentence in (8a) would yield the meaning representation in $(8 \mathrm{~b})$ :

(8) a. John entered the room.

b. $\left[_{\text {Event }}\right.$ GO $\left(\left[_{\text {Thing }}\right.\right.$ JOHN $]$, $\left[_{\text {Path }}\right.$ TO $\left(\left[_{\text {Place }}\right.\right.$ IN $\left(\left[_{\text {Thing }}\right.\right.$ ROOM $\left.\left.\left.\left.\left.\left.]\right)\right]\right)\right]\right)\right]$

Each pair of square brackets encloses a conceptual constituent, where the capitalized items denote the conceptual content, which is assigned to a major conceptual category like Thing, Place, Event, State, Path, Amount, etc. (Jackendoff 1983: 52ff). There are a number of possibilities for mapping these basic ontological categories onto functor-argument structures (Jackendoff 1990: 43). For example, the category Event can be elaborated into two-place functions like Go ([Thing], [Path]) or CAUSE ([Thing/Event], [Event]). Furthermore, each syntactic constituent maps into a conceptual constituent, and partly language-specific correspondence rules relate syntactic categories to the particular conceptual categories they can express. In later versions of Conceptual Semantics, these kinds of structures are enriched by referential features and modifiers, and the propositional structure is accompanied by a second tier encoding elements of information structure (cf. Jackendoff 1990: 55f; Culicover \& Jackendoff 2005: 154f).

A lexical entry consists of a phonological, syntactic, and conceptual representation. As can be seen in Fig. 2.6, most of the conceptual structure in ( $8 \mathrm{~b})$ is projected from the conceptual structure of the verb that provides a number of open argument slots (Jackendoff 1990: 46).

$\left[\begin{array}{l}\text { enter } \\ \mathrm{V}<\mathrm{NP}_{j}> \\ \left.\overline{[\text { Event }} \mathrm{GO}\left([\text { Thing }]_{i}\right),\left[\text { Path TO }\left(\left[\text { Place } \mathbb{N}\left(\left[\text { Thing }_{j}\right]_{j}\right)\right]\right]\right]\right]\end{array}\right]$
Fig. 2.6: Lexical entry for enter 
The conceptual structure is supplemented with a spatial structure that captures finer distinctions between lexical items in a way closely related to non-linguistic cognitive modules (Jackendoff 1990: 32ff; 2002: 345ff).

The same structure can also come about in a compositional way. While enter already includes the concept of a particular path (IN), this information is contributed by a preposition in the following example:

(9) a. John ran into the room.

b. $\left[_{\text {Event }}\right.$ GO $\left(\left[_{\text {Thing }}\right.\right.$ JOHN $\left.]\right),\left[_{\text {Path }}\right.$ TO $\left(\left[_{\text {Place }}\right.\right.$ IN $\left(\left[_{\text {Thing }}\right.\right.$ ROOM $\left.\left.\left.\left.\left.]\right)\right]\right)\right]\right]$

The corresponding lexical entries for the verb and the preposition (Fig. 2.7) account for the structure in (9b) (Jackendoff 1990: 45).

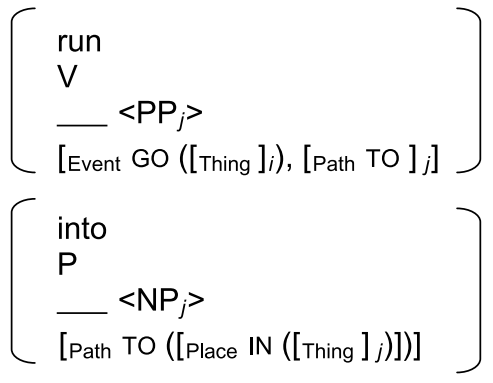

Fig. 2.7: Lexical entries for run and into

An important feature of Jackendoff's (1990: 25ff; 2002: 356ff) decompositions is the use of abstract location and motion predicates in order to represent the meaning of words outside the local domain. For example, a change-of-state verb like melt is rendered as 'to go from solid to liquid'. Building on Gruber's (1965) earlier work, Jackendoff thereby relates different classes of verbs by analogy. In Jackendoff (1983: 188), he states that in any semantic field in the domain of events and states "the principle event-, state-, path-, and place-functions are a subset of those used for the analysis of spatial location and motion". To make these analogies work, predicates are related to certain fields that determine the character of the arguments and the sort of inferences. For example, if the two-place function $\mathrm{BE}(\mathrm{x}, \mathrm{y})$ is supplemented by the field feature spatial, it indicates that $x$ is an object and $y$ is its location while the field feature possession indicates that $x$ is an object and $y$ the person who owns it. Only the latter one involves inferences about the rights of $y$ to use $x$ (Jackendoff 2002: 359ff).

Jackendoff (2002: 335f) dissociates himself from approaches that compare lexical decompositions with dictionary definitions; the major difference is that the basic elements of decompositions need not be words themselves, just as phonological features as the basic components on phonological elements are not 
sounds. He also claims that the speaker does not have conscious access to the decompositional structure of lexical items; this can only be revealed by linguistic analysis.

The question of what elements should be used in decompositions is answered to the effect that if the meaning of lexeme A entails the meaning of lexeme $\mathrm{B}$, the decomposition of A includes that of B (Jackendoff 1976). Jackendoff (2002: 336f) admits that it is hard to tell how the lower bound of decomposition can be determined. For example, some approaches consider CAUSE to be a primitive; others conceive of it as a family of concepts related through feature decomposition. In contrast to approaches that are only interested in finding those components that are relevant for the syntax-semantics interface, he argues that from the point of learnability the search for conceptual primitives has to be taken seriously beyond what is needed for the syntax. He takes the stance that it is just a matter of further and more detailed research before the basic components are uncovered.

\subsection{Linguistic phenomena}

Lexical decompositions within Conceptual Semantics serve much wider purposes than in many other approaches. First of all, they are considered a meaning representation in their own right, that is, not primarily driven by the need to explain linking and other linguistic interface phenomena. Moreover, as part of conceptual structure, they are linked not only to linguistic but also to non-linguistic cognitive domains.

As a semantic theory, Conceptual Semantics has to account for inferences. With respect to decompositions, this is done by postulating inference rules that link decompositional predicates. For example, from any decompositional structure involving $\mathrm{GO}(\mathrm{x}, \mathrm{y}, \mathrm{z})$, we can infer that $\mathrm{BE}(\mathrm{x}, \mathrm{y})$ holds before the Go event and $\mathrm{BE}(\mathrm{x}, \mathrm{z})$ after it. This is captured by inference rules as in (10a) that resemble meaning postulates in truth-conditional semantics (Jackendoff 1976: 114). Thus, we can infer from the train went from Kankakee to Mattoon that the train was in Kankakee before and in Mattoon after the event. Since other sentences involving a Go-type predicate like the road reached from Altoona to Johnstown do not share this inference, the predicates are subtyped to the particular fields transitional versus extensional. The extensional version of Go is associated with the inference that one part of $x$ in $\mathrm{GO}(\mathrm{x}, \mathrm{y}, \mathrm{z})$ is located in $y$ and the other in $z$ (10b) (Jackendoff 1976: 139):

(10) a. $\mathrm{GO}_{\text {Trans }}(\mathrm{x}, \mathrm{y}, \mathrm{z})$ at $t_{1} \Rightarrow$ for some times $t_{2}$ and $t_{3}$ such that $t_{2}<t_{1}<t_{3}$, $\mathrm{BE}_{\text {Trans }}(\mathrm{x}, \mathrm{y})$ at $t_{2}$ and $\mathrm{BE}_{\text {Trans }}(\mathrm{x}, \mathrm{z})$ at $t_{3}$. 
b. $\mathrm{GO}_{\mathrm{Ext}}(\mathrm{x}, \mathrm{y}, \mathrm{z}) \Rightarrow$ for some $v$ and $w$ such that $v \subset x$ and $w \subset x$, $\mathrm{BE}_{\mathrm{Ext}}(\mathrm{v}, \mathrm{y})$ and $\mathrm{BE}_{\mathrm{Ext}}(\mathrm{w}, \mathrm{z})$.

One of Jackendoff's main concerns is the mapping between conceptual and syntactic structure. Part of this mapping is the linking of semantic arguments into syntactic structures. In Conceptual Semantics this is done via thematic roles. Thematic roles are not primitives in Conceptual Semantics but can be defined on the basis of decompositions (Jackendoff 1972; 1987). They "are nothing but particular structural configurations in conceptual structure” (Jackendoff 1990: 47). For example, Jackendoff (1972: 39) identifies the first argument of the CAUSE relation with the agent role. In later versions of his theory, Jackendoff (e.g., 1990: 125ff) expands the conceptual structure of verbs by adding an action tier to the representation. While the original concept of decomposition (the 'thematic tier') is couched in terms of location and motion, thereby rendering thematic roles like theme, goal, or source, the action tier expresses how objects are affected and accounts for roles like actor and patient. Thus, hit as in the car hit the tree provides a theme (the car, the "thing in motion" in the example sentence) and a goal (the tree) on the thematic tier, and an actor (the car) and a patient (the tree) on the action tier. These roles can be derived from the representation in Fig. 2.8 (after Jackendoff 1990: 125ff).

$\left[\begin{array}{ll}\text { INCH }[\mathrm{BE}([\mathrm{CAR}],[\mathrm{AT}[\mathrm{TREE}]])] \\ \text { Event } & \text { AFF }([\mathrm{CAR}],[\mathrm{TREE}])\end{array}\right]$

Fig. 2.8: Thematic tier and action tier for the car hit the tree

The thematic roles derived from the thematic and the action tiers are ordered within a thematic hierarchy. This hierarchy is mapped onto a hierarchy of syntactic functions such that arguments are linked to syntactic functions according to the rank of their thematic role in the thematic hierarchy (Jackendoff 1990: 258, 268f; 2002: 143). Strict subcategorization can largely be dispensed with. However, Jackendoff (1990: 255ff; 2002: 140f) still acknowledges subcategorizational idiosyncrasies.

Among the many other phenomena treated within Conceptual Semantics and related to lexical decompositions are argument structure alternations (Jackendoff 1990: 71ff), aspectual-temporal adverbials and their relation to the boundedness of events (Jackendoff 1990: 27ff), the semantics of causation (Jackendoff 1990: 130ff), and phenomena at the border between adjuncts and arguments (Jackendoff 1990: 155ff). 


\subsection{Evaluation}

Jackendoff's approach to lexical decomposition has been a cornerstone in the development of lexical representations since it covers a wide domain of different classes of lexical items and phenomena associated with these classes. The wide coverage forced Jackendoff to expand the structures admitted in his decompositions. This in turn evoked criticism that his theory lacks sufficient restrictiveness. Furthermore, it has been criticized that the locational approach to decomposition needs to be stretched too far in order to make it convincing that it includes all classes of verbs (Levin 1995: 84). Wunderlich (1996: 171) considers Jackendoff's linking principle problematic since it cannot easily be applied to languages with case systems. In general, Jackendoff's rather heterogeneous set of correspondence rules has attracted criticism because it involves a considerable weakening of the idea of semantic compositionality (cf. article 4 [Semantics: Theories] (Jackendoff) Conceptual Semantics for Jackendoff's position).

\section{LCS decompositions and the MIT Lexicon Project}

\subsection{Origins and motivation}

An important contribution to the development of decompositional theories of lexical meaning originated in the MIT Lexicon Project in the mid-eighties. Its main proponents are Beth Levin and Malka Rappaport Hovav. Their approach is mainly concerned with the relation between semantic properties of lexical items and their syntactic behaviour. Thus, it aims at "developing a representation of those aspects of the meaning of a lexical item which characterize a native speaker's knowledge of its argument structure and determine the syntactic expression of its arguments" (Levin 1985: 4). The meaning representations were supposed to lead to definitions of semantic classes that show a uniform syntactic behaviour:

(1) All arguments bearing a particular semantic relation are systematically expressed in certain ways. (2) Predicates fall into classes according to the arguments they select and the syntactic expression of these arguments. (3) Adjuncts are systematically expressed in the same way(s) and their distribution often seems to be limited to semantically coherent classes of predicates. (4) There are regular extended uses of predicates that are correlated with semantic class. (5) Predicates belonging to certain semantic classes display regular alternations in the expression of their arguments. 
Proponents of the approach criticized accounts that were solely based on thematic roles, as they were incapable of explaining diathesis alternations (Levin 1985: 49ff; 1995: 76ff). Instead, they proposed decompositions on the basis of Jackendoff's (1972; 1976) conceptual structures, Generative Semantics, earlier work by Carter (1976) and Joshi (1974), and ideas from Hale \& Keyser (1987).

\subsection{Structure and location of decompositions}

The main idea in the early MIT Lexicon Project Working Papers was that two levels of lexical representation have to be distinguished, a lexical-semantic and a lexical-syntactic one (Rappaport, Laughren \& Levin 1987, later published as Rappaport, Levin \&Laughren 1993; Rappaport \& Levin 1988). The lexical-syntactic representation, PAS ("predicate argument structure"), "distinguishes among the arguments of a predicator only according to how they combine with the predicator in a sentence". PAS, which is subject to the projection principle (Rappaport \& Levin 1988: 16), expresses whether the role of an NP-argument is assigned (i) by the verb ("direct argument"), (ii) by a different theta role assigner like a preposition ("indirect argument"), or (iii) by the VP via predication ("external argument”) (Rappaport, Laughren \& Levin 1987: 3). These three modes of assignment are illustrated in the PAS for the verb put:
a. put, PAS: $\mathrm{x}<\underline{\mathrm{y}}, \mathrm{P}_{\mathrm{loc}} \mathrm{z}>$
b. put, $\mathrm{LCS}:[\mathrm{x}$ cause $[\mathrm{y}$ come to be at $\mathrm{z}]]$

The lexical-semantic basis of PAS is a lexical decomposition, LCS ("Lexical Conceptual Structure") (Rappaport, Laughren \& Levin 1987: 8). The main task for an LCS-based approach to lexical semantics is to find the mapping principles between LCS and PAS and between PAS and syntactic structure (Rappaport 1985: 146f).

Not all researchers associated with the MIT Lexicon Project distinguished two levels of representation. Carter (1988) refers directly to argument positions of predicates within decompositions in order to explain linking phenomena. In later work, Levin and Rappaport do not make reference to PAS as a level of representation anymore. The distinction between grammatically relevant and irrelevant lexical information is now reflected in a distinction between primitive predicates that are embedded in semantic templates, which are claimed to be part of Universal Grammar, and predicate constants, which reflect the idiosyncratic part of lexical meaning. The templates pick up distinctions known from Vendler classes (Vendler 1957) and are referred to as event structure representations. For 
example, (12a) is a template for an activity, and (12b) is a template for a particular kind of accomplishment (Rappaport Hovav \& Levin 1998: 108):

(12) a. $\left[\mathrm{X} \mathrm{ACT}_{<M A N N E R\rangle}\right]$

b. $\left[\left[\mathrm{x} \mathrm{ACT}_{<M A N N E R}\right]\right.$ CAUSE $\left.[\mathrm{BECOME}[\mathrm{y}<S T A T E>]]\right]$

The templates in (12) illustrate two main characteristics of this approach: templates can embed other templates and constants can function as modifiers of predicates (e.g., $<M A N N E R>$ with respect to ACT) or as arguments of predicates (e.g., $<S T A T E>$ with respect to BECOME). The representations are augmented by well-formedness conditions that require that each subevent in a template is represented by a lexical head in syntax and that all participants in lexical structure and all argument XPs in syntax are mapped onto each other. The principle of Template Augmentation makes it possible to build up complex lexical representations from simple ones such that the variants of sweep reflected in (13a-13c) are represented by the decompositions in (14a-14c):

(13) a. Phil swept the floor.

b. Phil swept the floor clean.

c. Phil swept the crumbs onto the floor.

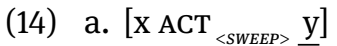

b. $[[\mathrm{x}$ ACT $<S W E E P>\underline{\mathrm{y}}]$ CAUSE $[\mathrm{BECOME}[\mathrm{y}<S T A T E>]]]$

c. $\left[\left[\mathrm{X}\right.\right.$ ACT $\left.{ }_{<S W E E P>} \underline{\mathrm{y}}\right]$ CAUSE [BECOME $\left.\left.[\mathrm{z}<P L A C E>]\right]\right]$

It is assumed that the nature of the constant can determine the range of templates that can be associated with it (cf. article 4 [this volume] (Levin \& Rappaport Hovav) Lexical Conceptual Structure).

It should be noticed that the approach based on LCS-type decompositions aims primarily at explaining the regularities of argument realization. Particularly in its later versions, it is not intended to capture different kinds of entailments, aspectual behaviour, or restrictions on adverbial modification. It is assumed that all and only those meaning components that are relevant to grammar can be isolated and represented as LCS templates.

\subsection{Linguistic phenomena}

Within this approach, most research was focused on argument structure alternations that verbs may undergo. 
(15) a. Bill loaded cartons onto the truck.

b. Bill loaded the truck with cartons.

With respect to alternations as in (15) Rappaport \& Levin (1988: 19ff) argued that a lexical meaning representation has to account for (i) the near paraphrase relation between the two variants, (ii) the different linking behaviour of the variants, (iii) and the interpretation of the goal argument in (15b) as completely affected by the action. They argued that a theta role approach could not fulfill these requirements: If the roles for load were considered identical for both variants, for example, <agent, locatum, goal>, requirement (i) is met but (ii) and (iii) are not since the different argument realizations cannot follow from identical theta role assignments and the affectedness component in (15b) is not expressed. If the roles for the two variants are considered different, for example, <agent, theme, goal > for (15a) versus <agent, locatum, goal> for (15b), the near paraphrase relation gets lost, and the completeness interpretation of (15b) still needs stipulative interpretation rules.

Within an LCS approach, linking rules make reference not to theta roles but to substructures of decompositions, for example, "When the LCS of a verb includes one of the substructures in [16], link the variable represented by $\mathrm{x}$ in either substructure to the direct argument variable in the verb's PAS.
a. ... [ $x$ come to be at LOCATION ] ...
b. ... [ x come to be in STATE ] ...” (Rappaport \& Levin 1988: 25)

With respect to load, it is assumed that the variant in (17b) with its additional meaning component of completion entails the variant in (17a) giving rise to the following representations:

(17) a. load: [ $\mathrm{x}$ cause [ $\mathrm{y}$ to come to be at $\mathrm{z}$ ]/LOAD ]

b. load: [ $\mathrm{x}$ cause [ $\mathrm{z}$ to come to be in STATE ]] BY MEANS OF [ $\mathrm{x}$ cause [ $\mathrm{y}$ to come to be at $\mathrm{z}$ ]] /LOAD ] (Rappaport \& Levin 1988: 26)

Assuming that the linking rules apply to the main clause within the decomposition, the two decompositions lead to different PAS representations in which the direct argument is associated with the theme in (18a) and the goal in (18b):
a. load: $\mathrm{x}<\underline{\mathrm{y}}, \mathrm{P}_{\mathrm{loc}} \mathrm{z}>$
b. load: $\mathrm{x}<\underline{\mathrm{z}}, \mathrm{P}_{\text {with }} \mathrm{y}>$

Thus the three observations, (i) near-paraphrase relation, (ii) different linking behaviour, and (iii) complete affectedness of the theme in one variant, are accounted for. 
Among the contemporary studies that proceeded in a similar vein are Hale \& Keyser's (1987) work on the middle construction and Guerssel et al.'s (1985) crosslinguistic studies on causative, middle, and conative alternations.

It is particularly noteworthy that Levin and Rappaport have greatly expanded the range of phenomena in the domain of argument structure alternations that a lexical semantic theory has to cover. Their empirical work on verb classes determined by the range of argument structure alternations they allow is documented in Levin (1993): About 80 argument structure alternations in English lead to the definition of almost 200 verb classes. The theoretical work represented by the template approach to LCS focuses on finding the appropriate constraints that guide the extension of verb meanings and explain the variance in argument structure alternations.

\subsection{Evaluation}

The work of Levin, Rappaport Hovav, and other researchers working with LCS-like structures had a large influence on later work on the syntax-semantics interface. By uncovering the richness of the domain of argument structure alternations, they defined what theories at the lexical syntax-semantic interface have to account for today. Among the work inspired by Levin and Rappaport Hovav's theory are approaches whose goal is to establish linking regularities on more abstract, structural properties of decompositions (e.g., Lexical Decomposition Grammar, cf. section 8) and attempts to integrate elements of lexical decompositions into syntactic structure (cf. section 9).

Levin and Rappaport Hovav's work is also typical of a large amount of lexical semantic research in the 1980s and 90s that has largely given up the semantic rigorousness characteristic of approaches based on formal semantics like Dowty (1979). Less rigorous semantic relations make theories more susceptible to circular argumentations when semantic representations are mapped onto syntactic ones (cf. article 7 [Semantics: Foundations, History and Methods] (Engelberg) Lexical decomposition, section 3.5). It has also been questioned whether Levin and Rappaport Hovav's approach allows for a principled account of cross-linguistic variation and universals (Croft 1998: 26; Zubizarreta \& Oh 2007: 8).

\section{Event Structure Theory}

\subsection{Origins and motivation}

In the late 1980s, two papers approaching verb semantics from a philosophical point of view inspired much research in the domain of aspect and Aktionsart, 
namely, Vendler's (1957) classification of expressions based on predicational aspect and Davidson's (1967) suggestion to reify events in order to explain adverbial modification. In connection with Dowty's (1979) work on decompositions within Montague semantics, the intensification of research on grammatical aspect, predicational aspect, and Aktionsarten also stimulated event-based research in lexical semantics. In particular, Pustejovsky's (1988; 1991a; 1991b) idea of conceiving of verbs as referring to structured events added a new dimension to decompositional approaches to verb semantics.

\subsection{Structure and location of decompositions}

According to Pustejovsky (1988; 1991a; 1991b), each verb refers to an event that can consist of subevents of different types, where 'processes' (P) and 'states' (S) are simple types that can combine to yield the complex type 'transition' $[\mathrm{P} \mathrm{S}]_{\mathrm{T}}$ via event composition. A process is conceived of as "a sequence of events identifying the same semantic expression", a state as "a single event, which is evaluated relative to no other event", and a transition as "an event identifying a semantic expression, which is evaluated relative to its opposition" (Pustejovsky 1991a: 56). In addition to this event structure (ES), Pustejovsky assumes a level LCS', where each subevent is related to a decomposition. Out of this, a third level of Lexical Conceptual Structure (LCS) can be derived, which contains a single lexical decomposition. The following examples illustrate how the meaning of sentences is based on these representational levels:

(19) a. Mary ran.

b. Mary ran to the store.

c. The door is closed.

d. The door closed.

e. John closed the door.

ES:

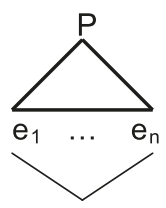

LCS': [ run(mary) ]

LCS: run(mary)

Fig. 2.9: Representation of Mary ran 
ES:

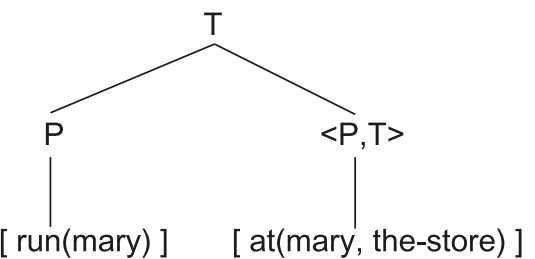

LCS: $\quad$ cause(act(mary), become(at (mary, the-store)) by run)

Fig. 2.10: Representation of Mary ran to the store

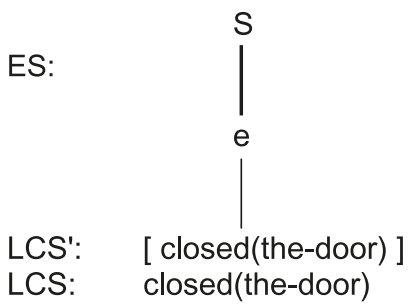

Fig. 2.11: Representation of the door is closed

ES:

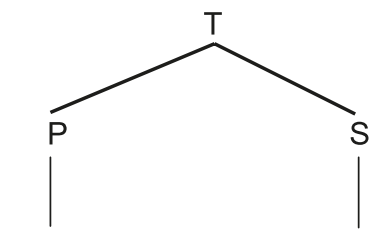

LCS': [ ᄀclosed(the-door) ] [ closed(the-door) ]

LCS: $\quad$ become(closed(the-door))

Fig. 2.12: Representation of the door closed

ES:

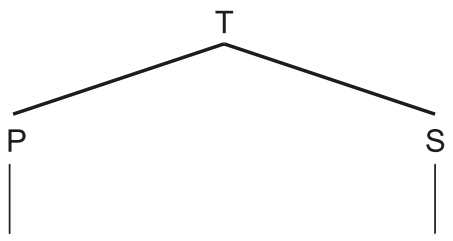

LCS': [ act(john, the-door) \& ᄀclosed(the-door) ] [ closed(the-door) ]

LCS: $\quad$ cause(act(john, the-door), become(closed(the-door)))

Fig. 2.13: Representation of John closed the door 
In terms of Vendler classes, Fig. 2.9 describes an activity, Fig. 2.11 a state, Figs. 2.10 and 2.13 accomplishments, and Fig. 2.12 an achievement. According to Pustejovsky, achievements and accomplishments have in common that they lead to a result state and are distinguished in that achievements do not involve an act-predicate at LCS'. As in many other decompositional theories (Jackendoff 1972; van Valin 1993), thematic roles are considered epiphenomenal and can be derived from the structured lexical representations (Pustejovsky 1988: 27).

Pustejovsky's event structure theory is part of his attempt to construct a theory of the Generative Lexicon (Pustejovsky 1995) that, besides Event Structure, also comprises Qualia Structure, Argument Structure, and Inheritance Structure (Pustejovsky 1991b, 1995). He criticises contemporary theories for focussing too much on the search for a finite set of semantic primitives:

Rather than assuming a fixed set of primitives, let us assume a fixed number of generative devices that can be seen as constructing semantic expressions. Just as a formal language is described in terms of the productions in the grammar rather than its accompanying vocabulary, a semantic language should be defined by the rules generating the structures for expressions rather than the vocabulary of primitives itself.

(Pustejovsky 1991a: 54)

\subsection{Linguistic phenomena}

The empirical coverage of Pustejovsky's theory is wider than many other decompositional theories: (i) The ambiguity of adverbials as in Lisa rudely departed is explained by attaching the adverb either to the whole transition $\mathrm{T}$ ('It was rude of Lisa to depart') or to the embedded process P ('Lisa departed in a rude manner') (Pustejovsky 1988: 31f). (ii) The mapping of Vendler classes onto structural event representations allows for a formulation of the restrictions on temporal-aspectual adverbials (in five minutes, for five minutes, etc.) (Pustejovsky 1991a: 73). (iii) The linking behaviour of verbs is related to LCS' components; for example, the difference between unaccusatives and unergatives is accounted for by postulating that a participant involved in a predicate opposition (as in Fig. 2.12) is mapped onto the internal argument position in syntax while the agentive participant in an initial subevent (as in Fig. 2.13) is realized as the external argument (Pustejovsky 1991a: 75). Furthermore, on the basis of Event Structure and Qualia Structure, a theory of aspectual coercion is developed (Pustejovsky \& Bouillon 1995) as well as an account of lexicalizations of causal relations (Pustejovsky 1995). 


\subsection{Evaluation}

Pustejovsky's concept of event structures has been taken up by many other lexical semanticists. Some theories included event structures as an additional level of representation. Grimshaw (1990) proposed a linking theory that combined a thematic hierarchy and an aspectual hierarchy of arguments based on the involvement of event participants in Pustejovsky-style subevents. In Lexical Decomposition Grammar, event structures were introduced as a level expressing sortal restrictions on events in order to explain the distribution and semantics of adverbials (Wunderlich 1996). It has sometimes been criticised that Pustejovsky's event structures were not fine-grained enough to explain adverbial modification. Consequently, suggestions have been made how to modify and extend event structures (e.g., Wunderlich 1996; cf. also Engelberg 2006).

Apart from those studies and theories that make explicit reference to Pustejovsky's event structures, a number of other approaches emerged in which phasal or mereological properties of events are embedded in lexical semantic representations, among them work by Tenny (1987; 1988), van Voorst (1988), Croft (1998), and some of the syntactic approaches to be discussed in section 9. Even standard lexical decompositions are often conceived of as event descriptions and referred to as 'event structures', for example, the LCS structures in Rappaport Hovav \& Levin (1998).

Event structures by themselves can of course not be considered full decompositions that exhaust the meaning of a lexical item. As we have seen above, they are always combined with other lexical information, for example, LCS-style decompositions or thematic role representations. Depending on the kind of representation they are attached to it is not quite clear if they constitute an independent level of representation. In Pustejovsky's approach, event structures are probably by and large derivable from the LCS structures they are linked to.

\section{Two-level Semantics and Lexical Decompositional Grammar}

\subsection{Origins and motivation}

Two-level-Semantics originated in the 1980s with Manfred Bierwisch, Ewald Lang and Dieter Wunderlich being its main proponents (Bierwisch 1982; 1989; 1997; Bierwisch \& Lang 1989; Wunderlich 1991; 1997a; cf. article 5 [Semantics: Theories] (Lang \& Maienborn) Two-level Semantics). In particular, Bierwisch's contribu- 
tion is remarkable for his attempt to define the role of the lexicon within Generative Grammar. Lexical Decomposition Grammar (LDG) emerged out of Two-level Semantics in the early 1990s. LDG has been particularly concerned with the lexical decompositon of verbs and the relation between semantic, conceptual, and syntactic structure. It has been developed by Dieter Wunderlich (1991; 1997a; 1997b; 2000; 2006) and other linguists stemming from the Düsseldorf Institute for General Linguistics (Stiebels 1996; 1998; 2006; Kaufmann 1995a; 1995b; 1995c; Joppen \& Wunderlich 1995; Gamerschlag 2005) - with contributions by Paul Kiparsky (cf. article 2 [Semantics: Interfaces] (Kiparsky \& Tonhauser) Semantics of inflection).

\subsection{Structure and location of decompositions}

Two-level semantics argues for separating semantic representations (semantic form, SF) that are part of the linguistic system, and conceptual representations that are part of the conceptual system (CS). Only SF is seen as a part of grammar that is integrated into its computational mechanisms while conceptual structure is a level of reasoning that builds on more general mental operations. How the interplay between SF and CS can be spelled out is shown in Maienborn (2003). She argues that spatial PPs can either function as event-external modifiers, locating the event as a whole as in (20a), or as event-internal modifiers, specifying a spatial relation that holds within the event as in (20b). While external event location is semantically straightforward, internal event location is subject to conceptual knowledge. Not only does the local relation expressed in (20b) require world knowledge about spatial relations in bike riding events, it is also reinterpreted as an instrumental relation that is not lexically provided by the verb or the preposition. Furthermore, in sentences like (20c) the external argument of the preposition, the woman's hand or some instrument the woman uses is not even mentioned in the sentence but has to be supplied by conceptual knowledge.

(20) a. Der Bankräuber ist auf der Insel geflohen. the bank robber has on the island escaped.

b. Der Bankräuber ist auf dem Fahrrad geflohen. the bank robber has on the bicycle escaped.

c. Maria zog Paul an den Haaren aus dem Zimmer. Maria pulled Paul at the hair out of the room.

Several tests show that event-internal modifiers attach to the edge of $V$ and event external modifiers to the edge of VP. Maienborn (2003: 487) suggests that the two 
syntactic positions trigger slightly different modification processes at the level of SF. While in both cases the lexical entries entering the semantic composition have the same decompositional representation $(21 \mathrm{a}, \mathrm{b})$, the process of external modification identifies the external argument of the preposition with the event argument of the verb (21c; $\lambda \mathrm{Q}$ applying to the $\mathrm{PP}, \lambda \mathrm{P}$ to the verb), whereas the process of internal modification turns the external argument of the preposition into a free variable, a so-called SF parameter (variable $v$ in 21d) that is specified as a constituent part (part-of) of what will later be instantiated with the event variable.
a. $\left[{ }_{\mathrm{P}}\right.$ auf]:
$\lambda y \lambda x$ [LOC (x, ON (y))]
b. $[$ fliehen]:
$\lambda \mathrm{x} \lambda \mathrm{e}$ [ESCAPE (e) \& THEME $(\mathrm{e}, \mathrm{x})]$
c. MOD:
$\lambda \mathrm{Q} \lambda \mathrm{P} \lambda \mathrm{x}[\mathrm{P}(\mathrm{x}) \& \mathrm{Q}(\mathrm{x})]$
d. MOD':
$\lambda \mathrm{Q} \lambda \mathrm{P} \lambda \mathrm{x}[\mathrm{P}(\mathrm{x}) \& \mathrm{PART}-\mathrm{OF}(\mathrm{x}, \mathrm{v}) \& \mathrm{Q}(\mathrm{v})]$

The compositional processes yield the representation in (22a) for the sentence (20b), the variable $v$ being uninstantiated. This representation will be enriched at the level of CS which falls back on a large base of shared conceptual knowledge. The utterance meaning is achieved via abduction processes which lead to the most economical explanation that is consistent with what is in the knowledge base. Spelling out the relevant part of the knowledge base, i.e. knowledge about spatial relations, about event types in terms of participants serving particular functions, and about the part-whole organization of physical objects, Maienborn shows how the CS representation for (20b), given in (22b), can be fomally derived (for details cf. Maienborn 2003: 492ff).
a. SF: $\quad \exists$ e [ESCAPE (e) \& THEME (e, r) \& BANK-ROBBER (r)
\& PART-OF (e, v) \& LOC (v, ON (b)) \& BIKE (b)]
b. CS:
ヨe [EXTR-MOVE (e) \& ESCAPE (e) \& THEME (e, r)
\& BANK-ROBBER (r) \& INSTR (e, b) \& VEHICLE (b)
\& BIKE (b) \& SUPPORT (b, r, $\tau(e))$ \& LOC (r, ON (b))]

The emergence of Lexical Decomposition Grammar out of Two-level Semantics is particularly interesting for the development of theories of decompositional approaches to verb meaning. LDG locates decompositional representations in semantics and rejects syntactic approaches to decomposition arguing that they have failed to provide logically equivalent paraphrases and an adequate account of scopal properties of adverbials (Wunderlich 1997a: 28f). It assumes four levels of representation: conceptual structure (CS), semantic form (SF), theta structure (TS), and morphological/syntactic structure (MS, in earlier versions of LDG also 
called phrase structure, PS). SF is a decomposition based on type logic that is related to CS by restrictive lexicalization principles; TS is derived from SF by lambda abstraction and encodes the argument hierarchy. TS in turn is mapped onto MS by linking principles (Wunderlich 1997a: 32; 2000: 249ff). The four levels are illustrated in Fig. 2.14 with respect to the German verb geben 'give' in (23).

(23) a. (als) [der Torwart [dem Jungen [den Ball gab]]]

(when) the goalkeeper the boy the ball gave

b. $\left[\mathrm{DP}^{\mathrm{x}}{ }_{\text {NOM }}\left[\mathrm{DP}_{\mathrm{DAT}}^{\mathrm{y}}\left[\mathrm{DP}_{\mathrm{ACC}}^{\mathrm{z}}\right.\right.\right.$ geb-AGR $\left.\left.\left.{ }^{\mathrm{x}}\right]\right]\right]$

\begin{tabular}{|c|c|c|c|}
\hline \multicolumn{3}{|l|}{ TS } & \multirow{2}{*}{$\begin{array}{l}\text { SF } \\
\{A C T(X) \& B E C P O S S(Y, Z)\}(S)\end{array}$} \\
\hline \multirow{2}{*}{$\begin{array}{l}\lambda z \\
+h r \\
-I r\end{array}$} & \multirow{2}{*}{$\begin{array}{l}\lambda y \\
+h r \\
+l r\end{array}$} & \multirow{2}{*}{$\begin{array}{rr}\lambda x & \lambda s \\
-h r & \\
+l r & \end{array}$} & \\
\hline & & & \\
\hline \multirow[b]{2}{*}{$\downarrow$} & \multirow[b]{2}{*}{$\downarrow$} & \multirow[b]{2}{*}{$\downarrow$} & CS \\
\hline & & & $\begin{array}{l}x=\text { Agent or Controller } \\
y=\text { Recipient }\end{array}$ \\
\hline ACC & DAT & $\begin{array}{l}\text { AGR } \\
\text { NOM }\end{array}$ & $\begin{array}{l}\mathrm{z}=\text { Patient or Affected } \\
\text { Causal event: } \mathrm{ACT}\left(\mathrm{x}, \mathrm{S}_{1}\right)\end{array}$ \\
\hline \multicolumn{3}{|l|}{ MS } & Result state: $\operatorname{poss}(y, z)\left(s_{2}\right)$ \\
\hline
\end{tabular}

Fig. 2.14: The representational levels of LDG (Wunderlich 2000: 250)

Semantic form does not provide a complete characterization of a word's meaning. It serves to represent those properties of predicate-argument structures that make it possible to account for their grammatical properties (Wunderlich 1996: 170). This level of representation must be finite and not subject to contingent knowledge. In contrast to semantic form, conceptual structures draw on an infinite set of properties and can be subject to contingent knowledge (Wunderlich 1997a: 29). Since SF decompositions consist of hierarchically ordered binary structures assuming that a \& b branches as [a [\& b]] - arguments can be ranked according to how deeply they are embedded within this structure. TS in turn preserves the SF hierarchy of arguments in inverse order so that arguments can be discharged by functional application (Wunderlich 1997a: 44). Each argument role in TS is characterized as to whether there is a higher or lower role.

Besides their thematic arguments, nouns and verbs also have referential arguments, which do not undergo linking. Referential arguments are subject to sortal restrictions that are represented as a structured index on the referential argument (Wunderlich 1997a: 34). With verbs, this sortal index consists of an 
event structure, similar in form to Pustejovsky's event structures but slightly differing with respect to the distinctions expressed (Wunderlich 1996: 175ff).

The relation between the different levels is mediated by a number of principles. For example, ARgument HiERARCHy regulates the inverse hierarchical mapping from SF to TS, and COHERENCE requires that the subevents corresponding to SF predicates be interpreted as contemporaneous or causally related (Kaufmann 1995c). Thus, the causal interpretation of geben in (23) is not explicitly given in SF but left to COHERENCE as a general CS principle of interpretation.

\subsection{Linguistic phenomena}

The main concern of LDG is argument linking, and its basic assumption is that syntactic properties of arguments follow from hierarchical structures within semantic form. Structural linking is based on the assignment of two binary features to the arguments in TS, $[ \pm \mathrm{hr}]$ 'there is a / no higher role' and [ $\pm \mathrm{lr}]$ 'there is a / no lower role'. The syntactic features are associated with these two binary features, dative with $[+\mathrm{hr},+\mathrm{lr}]$, accusative with [+hr], ergative with [+lr], and nominative/absolutive with [ ] (cf. Fig. 2.14). All and only the structural arguments have to be matched with a structural linker. Besides structural linking, it is taken into account that arguments can be suppressed or realized by oblique markers. This also motivates the distinction between SF and TS (Wunderlich 1997b: 47ff; 2000: 252). The following examples show how structural arguments are matched with structural linkers in nominative-accusative (NA) and absolutive-ergative (AE) languages (Wunderlich 1997a: 49):

(24) a. intransitive verbs: $\quad \lambda x$

$$
\text { [-hr, -lr] }
$$

NA: nom

AE: abs

b. transitive verbs:

$\lambda y$ $\lambda \mathrm{x}$

[+hr, -lr] $\quad[-\mathrm{hr},+\mathrm{lr}]$

NA: acc nom

c. ditransitive verbs:

$\mathrm{AE}: \quad \mathrm{abs}$

NA: acc

$\begin{array}{lll}\lambda z & \lambda y & \lambda x \\ {[+h r,-l r]} & {[+h r,+l r]} & {[-h r,+l r]}\end{array}$

AE: abs dat erg 
LDG pursues a strictly lexical account of argument extensions such as possessors, beneficiaries, or arguments introduced by word formation processes or resultative formation. These argument extensions are all handled within SF formation by adding predicates to an existing SF (Stiebels 1996; Wunderlich 2000). Thus, the complex verb in (25a) is represented as the complex SF (25c) on the basis of (25b) and an argument extension principle.

(25) a. Sie erschrieb sich den Pulitzer-Preis. she "er"-wrote herself the Pulitzer Prize 'She won the Pulitzer Prize by her writing.'

b. schreib- 'write': $\lambda \mathrm{y} \lambda \mathrm{x} \lambda \mathrm{s}$ WRITE $(\mathrm{x}, \mathrm{y})(\mathrm{s})$

c. erschreib: $\lambda \mathrm{v} \lambda \mathrm{u} \lambda \mathrm{x} \lambda \mathrm{s} \exists \mathrm{y}\{\operatorname{WRITE}(\mathrm{x}, \mathrm{y})(\mathrm{s}) \& \operatorname{BECOME} \operatorname{POSs}(\mathrm{u}, \mathrm{v})\}(\mathrm{s})$

These processes are restricted by two constraints on possible verbs, COHERENCE and ConNEXION, the latter one requiring that each predicate in SF share at least one, possibly implicit, argument with another predicate in SF (Kaufmann 1995c). In (25c), CoHEREnCE guarantees the causal interpretation, and ConNExion accounts for the identification of the agent of writing with the possessor of the prize. The resulting SF is then subject to ARGUMENT HIERARCHY and the usual linking principles. As we have seen in (25c), the morphological operation adds semantic content to SF as it does with other operations like resultative formation. In other cases, morphology operates on TS in order to change linking conditions (e.g., passive) (Wunderlich 1997a: 52f).

During the last 20 years, LDG has produced numerous studies on phenomena in a number of typologically diverse languages, dealing with agreement (Wunderlich 1994), word formation of verbs (Wunderlich 1997b; Stiebels 1996; Gamerschlag 2005), locative verbs (Kaufmann 1995a), causatives and resultatives (Wunderlich 1997a; Kaufmann 1995a), dative possessors (Wunderlich 2000), ergative case systems (Joppen \& Wunderlich 1995), and nominal linking (Stiebels 2006).

\subsection{Evaluation}

In contrast to some other decompositional approaches, LDG adheres to a compositional approach to meaning and tries to define its relation to current syntactic theories. In more recent publications (Stiebels 2002; Gamerschlag 2005), LDG has been reformulated within an optimality theoretic framework. Lexical Decomposition Grammar is criticized by Taylor (2000), in particular for its division between semantic and conceptual knowledge. LDG, based on Two-level 
Semantics, accounts for the different readings of a lexical item within conceptual structure, leaving lexical entries largely monosemous. Taylor argues that lexical usage is to a large degree conventionalized and that the particular readings a word does or does not have cannot be construed entirely from conceptual knowledge. Bierwisch (2002) presents a number of arguments against the removal of CAUSE from SF decompositions. Further problems, emerging from structural stipulations, are discussed in article 7 [Semantics: Foundations, History and Methods] (Engelberg) Lexical decomposition, section 3.5.

\section{Natural Semantic Metalanguage}

\subsection{Origins and motivation}

The theory of Natural Semantic Metalanguage (NSM) originated in the early seventies. Its main proponents have been Anna Wierzbicka (1972; 1980; 1985; 1992; 1996) and Cliff Goddard (1998; 2006; 2008a; Goddard \& Wierzbicka 2002). NSM theory has been developed as an attempt to construct a semantic metalanguage (i) that is expressive enough to cover all the word meanings in natural languages, (ii) that allows noncircular reductive paraphrases, (iii) that avoids metalinguistic elements that are not part of the natural language it describes, (iv) that is not ethnocentric, and (v) that makes it possible to uncover the universal properties of word meanings (cf. for an overview Goddard 2002a; Durst 2003). In order to achieve this, Wierzbicka suggested that the lexicon of a language can be divided into a small set of indefinable words (semantic primes) and a large set of words that can be defined in terms of these indefinables.

\subsection{Structure and location of decompositions}

The term Natural Semantic Metalanguage is intended to reflect that the semantic primes used as a metalanguage are actual words of the object language. The indefinables constitute a finite set and, although they are language-specific, each language-specific set "realizes, in its own way, the same universal and innate alphabet of human thought" (Wierzbicka 1992: 209). More precisely, this implies that the set of semantic primes of a particular language and their combinatorial potential have the expressive power of a full natural language and that the sets of semantic primes of all languages are isomorphic to each other. The set of semantic primes consists of 60 or so elements including such words as you, this, two, good, know, see, word, happen, die, after, near, if, very, kind of, and like, each 
disambiguated by a canonical context (cf. Goddard 2008b). These primes are claimed to be indefinable and indispensable (cf. Goddard \& Wierzbicka 1994b; Wierzbicka 1996; Goddard 2002b; Wierzbicka 2009). Meaning descriptions within NSM theory look like the following (Wierzbicka 1992: 133):

(26) a. (X is embarrassed)

b. $\mathrm{X}$ thinks something like this:

something happened to me now.

because of this, people here are thinking about me.

I don't want this.

because of this, I would want to do something.

I don't know what I can do.

I don't want to be here now.

because of this, $\mathrm{X}$ feels something bad.

It is required for the relationship between the defining decomposition and the defined term that they be identical in meaning. This is connected to substitutability; the definiens and the definiendum are supposed to be replaceable by each other without change of meaning (Wierzbicka 1988: 12).

\subsection{Linguistic phenomena}

More than any other decompositional theory, NSM theory resembles basic lexicographic approaches to meaning, in particular, those traditions of English learner lexicography in which definitions of word meanings are restricted to the non-circular use of a limited "controlled" defining vocabulary (e.g., Summers 1995). Thus, it is not surprising that NSM theory tackles word meanings in many semantic fields that have not been at the centre of attention within other decompositional approaches, for example, pragmatically complex domains like speech act verbs (Wierzbicka 1987). Other investigations focus on the cultural differences reflected in words and their alleged equivalents in other languages, for example, Wierzbicka's (1999) study on emotion words. NSM theory also claims to be able to render the meaning of syntactic constructions and grammatical categories by decompositions. An example is given in (27).

(27) a. ['first person plural exclusive']

b. I'm thinking of some people.

I am one of these people. you are not one of these people. (Goddard 1998: 299) 
The claim of NSM theory to be particularly apt as a means to detect subtle cross-linguistic differences is reflected in Goddard \& Wierzbicka (1994a), where studies on a fairly large number of typologically and genetically diverse languages are presented.

\section{4 evaluation}

While many of its critics acknowledge that NSM theory has provided many insights into particular lexical phenomena, its basic theoretical assumptions have often been subject to criticism. It has been called into question whether the emphasis on giving dictionary-style explanations of word meanings is identical to uncovering the native speaker's knowledge about word meaning. NSM theory has also been criticized for not putting much effort into providing a foundation for the theory on basic semantics concepts (cf. Riemer 2006: 352). The lack of a theory of truth, reference, and compositionality within NSM theory raised severe doubts about whether it can adequately deal with phenomena like quantification, anaphora, proper names, and presuppositions (Geurts 2003; Matthewson 2003; Barker 2003). This criticism also affects the claim of the theory to be able to cover the semantics of the entire lexicon of a language.

\section{Lexical Relational Structures}

\subsection{Origins and motivation}

With the decline of Generative Semantics in the 1970s, lexical approaches to decomposition began to dominate the field. These approaches enriched our understanding of the complexity of lexical meaning as well as the possibility of generalizations across verb classes. Then, in the late 1980s, syntactic developments within the Principles \& Parameter framework suggested more complex structures within the VP. The assumption of VP-internal subjects and, in particular, Larson's (1988) theory of VP-shells as layered VP-internal structures suggested the possibility to align certain bits of verb-internal semantic structure with structural positions in layered VPs. With these developments underway, the time was ripe for new syntactic approaches to decomposition (cf. also the summary in Levin \& Rappaport Hovav 2005: 131ff). 


\subsection{Structure and location of decompositions}

On the basis of data from binding, quantification, and conjunction with respect to double object constructions, Larson (1988: 381) argues for the SINGLE ARGUMENT HYPOTHESIS, according to which a head can only have one argument. This forces a layered structure with multiple heads within VP. Fig. 2.15 exhibits the structure of Mary gave a box to Tom within this VP-shell. The verb moves to the higher V node by head-movement. The mapping of a verb's arguments onto the nodes within the VP-shell is determined by a theta hierarchy 'AGENT > THEME > GOAL > OBLIQUES' such that the lowest role of a verb is assigned to the lowest argument position, the next lowest role to the next lowest argument position, and so on (Larson 1988: 382). Thus, there is a weak correspondence between structural positions and verb semantics in the sense that high argument positions are associated with a comparatively high thematic value. However, structural positions within VP shells are not linked to any stable semantic interpretation.

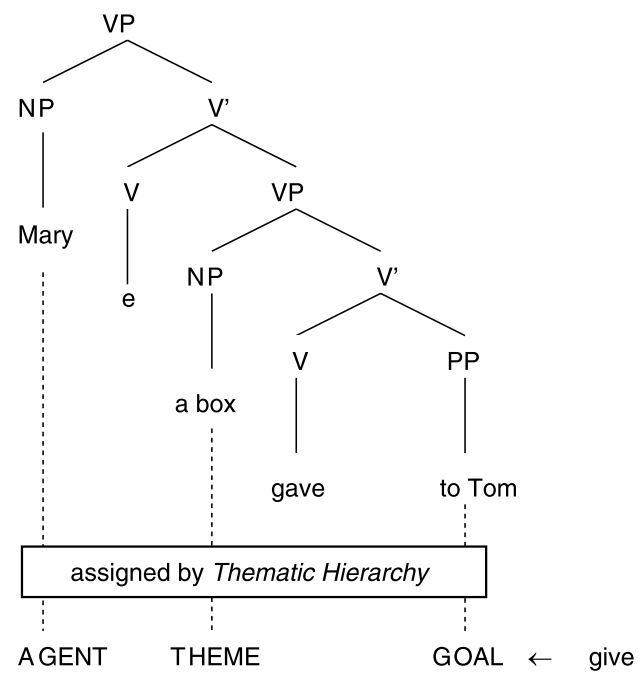

Fig. 2.15: VP-shell and theta role assignment

Larsonian shells inspired research on the syntactic representation of argument structure. Particularly influential was the approach pursued by Hale \& Keyser (1993; 1997; 2002). They assume that argument structure is handled within a lexicon component called l-syntax, which is an integral part of syntax as it obeys syntactic principles. The basic assumption is that argument structure, also called "lexical relational structure", is defined in reference to two possible relations 
between a head and its arguments, namely, the head-complement and the head-specifier relation (Hale \& Keyser 1999: 454). Each verb projects an unambiguous structure in 1-syntax. In Fig. 2.16, the lexical relational structure of put as in put the books on the shelf is illustrated.

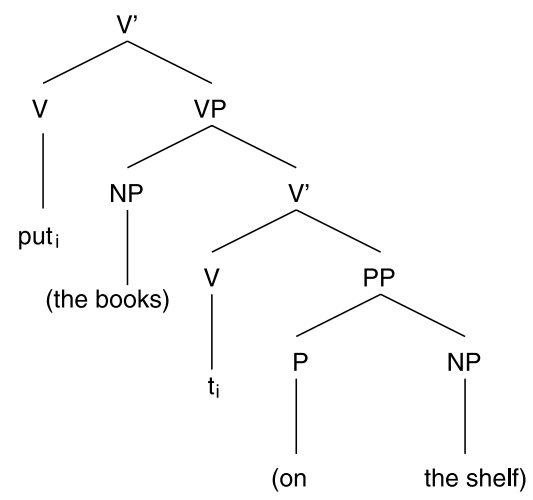

Fig. 2.16: Lexical relational structure of put and head movement of the verb

Primary evidence for this approach is taken from verbs that are regarded as denominal. Locational verbs of this sort such as to shelve, to box, or to saddle receive a similar representation as to put. The Lexical Relational Structure of shelve consists of Larsonian VP-shells with the noun shelf as complement of the embedded prepositional head. From there, the noun incorporates into an abstract V head by head movement (cf. Fig. 2.17). (Hale \& Keyser 1993: 55ff)

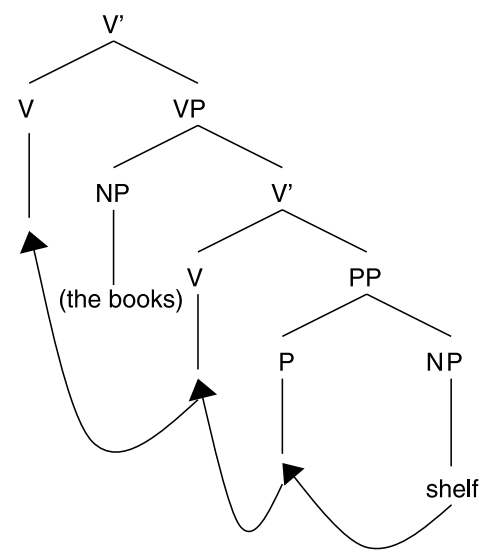

Fig. 2.17: Lexical relational structure of shelve and incorporation of the noun 
In a similar way, unergative verbs like sneeze or dance (28b), which are assumed to have a structure parallel to expressions like make trouble or have puppies (28a), are derived by incorporation of a noun into a V head (Hale \& Keyser 1993: 54f).

(28) a. [have $\left.{ }_{\mathrm{v}}\left[\text { puppies }_{\mathrm{N}}\right]_{\mathrm{NP}}\right]_{\mathrm{V}^{\prime}}$

b. $\left[\text { sneeze }_{\mathrm{iv}}\left[\mathrm{t}_{\mathrm{iN}}\right]_{\mathrm{NP}}\right]_{\mathrm{V}^{\prime}}$

Hale \& Kayser (1993: 68) assume that "elementary semantic relations" are "associated" with these syntactic structures: The agent occurs in a Spec position above VP, the theme in a Spec position of a V that takes a PP/AP complement, and so forth. The argument structure of shelve is thus related to semantic relations as exhibited in Fig. 2.18.

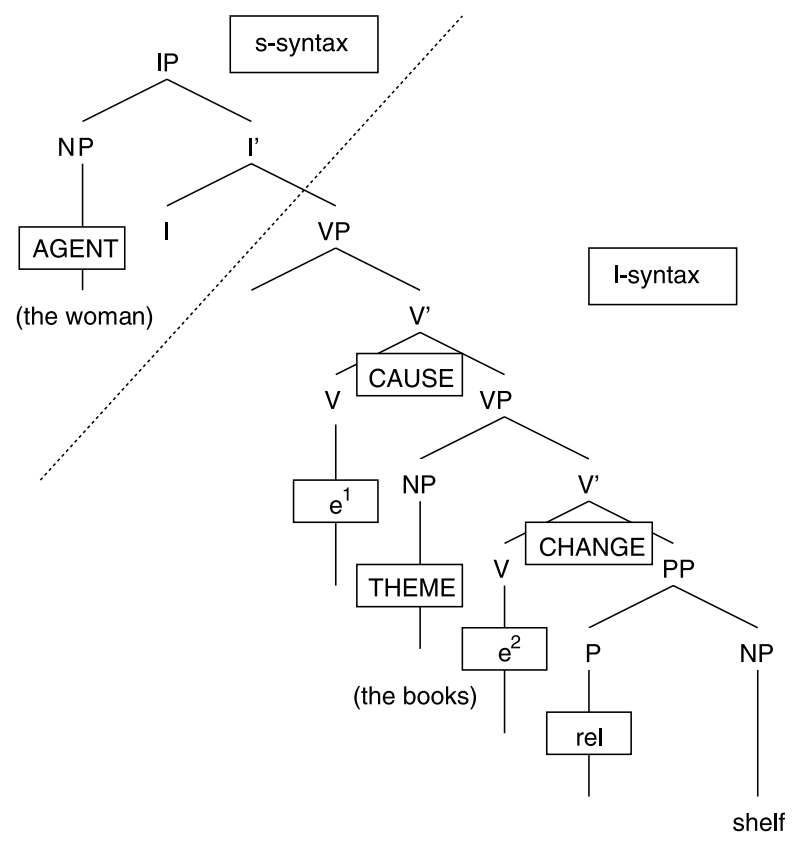

Fig. 2.18: Semantic relations associated with lexical relational structures (after Hale \& Keyser 1993: 76ff)

It is important to keep in mind that Hale and Keyser do not claim that argument structures are derived from semantics. On the contrary, they assume that "certain meanings can be assigned to certain structures" in the sense that they are fully determined by l-syntactic configurations (Hale \& Keyser 1993: 68; 1999: 463).

Fig. 2.18 also reflects two important points of Hale and Keyser's theory. Firstly, they assume a central distinction between verb classes: Contrary to the 
early exploration of VP structures as in Fig. 2.17, unergatives and transitives in contrast to unaccusatives are assumed not to have a subject as part of their argument structure; their subjects are assigned in s-syntax (Hale \& Keyser 1993: 76ff). Secondly, Hale and Kayser emphasize that their approach explains why the number of theta roles is (allegedly) so small, namely, because there is only a very restricted set of syntactic configurations with which they can be associated.

\subsection{Linguistic phenomena}

Hale and Keyser's approach aims to explain why certain argument structures are possible while others are not. For example, it is argued that sentences like (29a) are ungrammatical because incorporation of a subject argument violates the Empty Category Principle (Hale \& Keyser 1993: 60). The ungrammaticality of (29b) is accounted for by the assumption that unergatives as in (28) do not project a specifier that would allow a transitivity alternation (Hale \& Keyser 1999: 455). (29c) is argued to be ungrammatical because the Lexical Relational Structure would have to be parallel to she gave a church her money, in which church occupies Spec,VP, the "subject" position of the inner VP. Incorporation from this position violates the Empty Category Principle. By the same reasoning, she flattened the metal is wellformed, incorporating flat from an AP in complement position while (29d) is not since metal would have to incorporate from an inner subject position.

(29) a. *It cowed a calf. (with the meaning 'a cow calved' and it as expletive)

b. *An injection calved the cow early.

c. ${ }^{\star}$ She churched the money.

d. * She metalled flat.

This incorporation approach allows Hale and Keyser to explore the parallels in syntactic behaviour between expressions like give a laugh and laugh which, besides being near-synonymous, both fail to transitivize, as well as the differences between expressions like make trouble and thicken soups where only the latter allows middles and inchoatives.

\subsection{Evaluation}

Hale and Keyser's work has stimulated a growing body of research aiming at a syntactification of notions of thematic roles, decompositional and aspectual structures. Some prominent examples are Mateu (2001), Alexiadou \& Anagnostopoulou (2004), Erteschik-Shir \& Rapoport (2005; 2007), Zubizarreta \& Oh (2007), 
and Ramchand's (2008) first phase syntax. Some of this work places a strong emphasis on aspectual structure, for example, Ritter \& Rosen (1998) and Travis (2000). As Travis (2000: 181f) argues, the new syntactic approaches to decompositions avoid many of the pitfalls of Generative Semantics, which is certainly due to a better understanding of restrictive principles in recent syntactic theories.

However, Hale and Keyser's work has also attracted heavy criticism from proponents of Lexical Conceptual Structure (e.g., Culicover \& Jackendoff 2005, Rappaport Hovav \& Levin 2005), Two-level Semantics (e.g., Bierwisch 1997; Kiparsky 1997) as well as from anti-decompositionalist positions (e.g., Fodor \& Lepore 1999). The analyses themselves raise many questions. For example, it remains unexplained which principles exclude a lexical structure of a putative verb to church (29c) along the lines of she gave the money to the church, that is, a structure parallel to the one suggested for to shelve (cf. also Kiparsky 1997: 481). It has also been observed that the position allegedly vacated by the noun in structures as in Fig. 2.18 can actually show lexical material as in Joe buttered the toast with rancid butter (Culicover \& Jackendoff 2005: 102). Many other analyses and assumptions have also been under attack, among them assumptions about which verbs are denominal and how their meanings come about (Kiparsky 1997: 485ff; Culicover \& Jackendoff 2005: 55) as well as predictions about possible transitivity alternations (Kiparsky 1997: 491). Furthermore, one can of course doubt that the number of different theta roles is as small as Hale and Keyser assume. More empirically oriented approaches to verb semantics come to dramatically different conclusions (cf. Kiparsky 1997: 478 or work on Frame Semantics like Ruppenhofer et al. 2006). Even some problems from Generative Semantics reemerge, such as that expressions like put on a shelf and shelve are not synonymous, the latter being more specific (Bierwisch 1997: 260). Overgeneralization is not accounted for, either. The fact that there is a verb to shelve but no semantically corresponding verb to basket points to a location of decomposition in the lexicon (Bierwisch 1997: 232f). Reacting to some of the criticism, Hale \& Keyser (2005) later modified some assumptions of their theory; for example, they abandoned the idea of incorporation in favour of a locally operating selection mechanism.

\section{Distributed Morphology}

\subsection{Origins and motivation}

Hale \& Keyser (1993) and much research inspired by them have attempted to reduce the role of the lexicon in favour of syntactic representations. An even more radical anti-lexicalist approach is pursued by Distributed Morphology (DM), 
which started out in Halle \& Marantz (1993) and since then has been elaborated by a number of DM proponents (Marantz 1997; Harley 2002; Harley \& Noyer 1999; 2000; Embick 2004; Embick \& Noyer 2007) (cf. also article 5 [Semantics: Interfaces] (Harley) Semantics in Distributed Morphology).

\subsection{Structure and location of decompositions}

According to Distributed Morphology, syntax does not combine words but generates structures by combining morphosyntactic features. Terminal nodes, so-called "morphemes", are bundles of these morphosyntactic features. DM distinguishes f-nodes from l-nodes. F-nodes correspond to what is traditionally known as functional, closed-class categories; their insertion at spell-out is deterministic. L-nodes correspond to lexical, open-class categories; their insertion is not deterministic. Vocabulary items are only inserted at spell-out. These vocabulary items are minimally specified in that they only consist of a phonological string and some information where this string can be inserted (cf. Fig. 2.19).

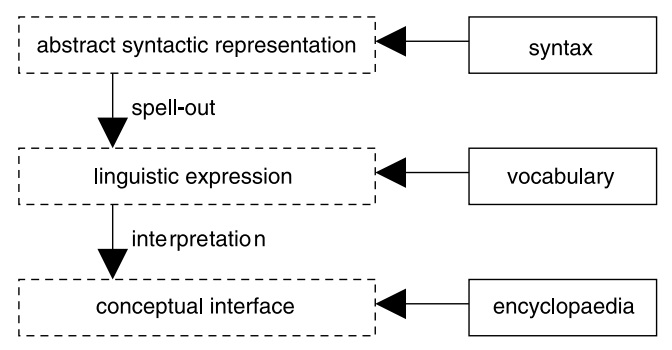

Fig. 2.19: The architecture of distributional morphology cf. Harley \& Noyer 2000: 352; Embick \& Noyer 2007)

Neither a syntactic category nor any kind of argument structure representation is included in vocabulary entries as can be seen in example (30a) from Harley \& Noyer (1999: 3). The distribution information in the vocabulary item replaces what is usually done by theta-roles and selection. In addition to the Vocabulary, there is a component called Encyclopaedia where vocabulary items are linked to those aspects of meaning that are not completely predictable from morphosyntactic structure (30b).

(30) a. Vocabulary item: /dog/: [Root] [+count] [+animate] ...

b. Encyclopaedia item: dog: four legs, canine, pet, sometimes bites etc... chases balls, in environment "let sleeping s lie”, refers to discourse entity who is better left alone... 
While the formal information in vocabulary items in part determines grammatical well-formedness, the encyclopaedic information guides the appropriate use of expressions. For example, the oddness of (31a) is attributed to encyclopaedic knowledge. The sentence is pragmatically anomalous but interpretable: It could refer to some unusual telepathic transportation event. (31b), on the other hand, is considered ungrammatical because put is not properly licensed and, therefore, uninterpretable under any circumstances (Harley \& Noyer 2000: 354).

(31) a. Chris thought the book to Mary.

b. *James put yesterday.

Part of speech is reflected in DM by the constellation in which a root morpheme occurs. For example, a root is a noun if its nearest c-commanding f-node is a determiner and a verb if its nearest c-commanding f-nodes are $v$, aspect, and tense. Not only are lexical entries more reduced than in approaches based on Hale \& Keyser (1993), there is also no particular part of syntax corresponding to l-syntax (cf. for this overview Harley \& Noyer 1999, 2000; Embick \& Noyer 2007).

\subsection{Linguistic phenomena}

Distributed Morphology has been applied to all kinds of phenomena in the domain of inflectional and derivational morphology. Some work has also been done with respect to the argument structure of verbs and nominalizations. One of the main topics in this area is the explanation of the range of possible argument structure alternations. A typical set of data is given in (32) and (33) (taken from Harley \& Noyer 2000: 362).

(32) a. John grows tomatoes.

b. Tomatoes grow.

c. The insects destroyed the crop.

d. *The crops destroyed.

(33) a. the growth of the tomatoes.

b. the tomatoes' growth.

c. *John's growth of the tomatoes.

d. the crop's destruction.

e. the insects' destruction of the crop. 
It has to be explained why grow, but not destroy, has an intransitive variant and why destruction, but not growth, allows the realization of the causer argument in Spec, DP (for the following, cf. Harley \& Noyer 2000: 356ff). Syntactic structures are based on VP-shells. For each node in these structures, there is a set of possible items that can fill this position (with LP corresponding approximately to VP):
$\underline{\text { node }}$
possible filling
a. Spec, $v \mathrm{P}$
DP, $\varnothing$
b. $\quad v$ head
HAPPEN/BECOME, CAUSE, BE
c. Spec,LP
DP, $\varnothing$
d. L head
l-node
e. Comp,LP
DP, $\varnothing$

Picking from this menu, a number of different syntactic configurations can be created:

\begin{tabular}{|c|c|c|c|c|c|}
\hline$\underline{\text { Spec, }, v \mathrm{P}}$ & $\underline{\mathrm{v}}$ & Spec,LP & $\underline{\mathrm{L}}$ & Comp,LP & (example) \\
\hline DP & CAUSE & $\varnothing$ & 1 & DP & grow (tr.) \\
\hline$\varnothing$ & BECOME & $\varnothing$ & 1 & DP & grow (itr.) \\
\hline DP & CAUSE & $\varnothing$ & 1 & DP & destroy \\
\hline DP & CAUSE & DP & 1 & DP & give \\
\hline$\varnothing$ & BECOME & $\varnothing$ & 1 & DP & arrive \\
\hline$\varnothing$ & $\mathrm{BE}$ & DP & 1 & DP & know \\
\hline
\end{tabular}

The items filling the $v$ head are the only ones conceived of as having selectional properties: CAUSE, but not BECOME or BE, selects an external argument. The grammaticality of the configurations in (35) is also determined by the licensing environment specified in the Vocabulary (cf. Fig. 2.20).

\begin{tabular}{|c|c|c|}
\hline \multicolumn{2}{|c|}{ VOCABULARY } & ENCYCLOPAEDIA \\
\hline Phonology & Licensing environment & \\
\hline destroy & {$[+v],[+\mathrm{DP}],[+$ cause $] \leftarrow$} & $\rightarrow$ what we mean by destroy \\
\hline grow & {$[+v],[+D P],[ \pm$ cause $]$} & what we mean by grow \\
\hline $\sin k$ & {$[ \pm v],[+D P],[ \pm$ cause $]$} & what we mean by sink \\
\hline open & {$[ \pm v],[+D P],[ \pm$ cause $]$} & $\rightarrow$ what we mean by open \\
\hline arrive & {$[+v],[+D P],[-$ cause $]$} & $\rightarrow$ what we mean by arrive \\
\hline
\end{tabular}

Fig. 2.20: Vocabulary and encyclopaedic entries of verbs (after Harley \& Noyer 2000: 361) 
Thus, the transitive and intransitive uses of the roots in (32a) through (32c) are reflected in the syntactic structures in (36), where CAUSE and BECOME are realized as zero morphemes (cf. article 5 [Semantics: Interfaces] (Harley) Semantics in Distributed Morphology) and the LP head is assumed to denote a resulting state:

(36) a. $\left[_{v \mathrm{P}}[\mathrm{DP}\right.$ John $]\left[_{v^{\prime}}\right.$ CAUSE $\left[\right.$ LP grown $\left[{ }_{\mathrm{DP}}\right.$ tomatoes $\left.\left.\left.]\right]\right]\right]$

b. $\left[{ }_{v^{\prime}}\right.$ BECOME $\left[\right.$ LP grown $\left[{ }_{D P}\right.$ tomatoes $\left.\left.]\right]\right]$

c. $\left[_{v \mathrm{P}}[\mathrm{DP}\right.$ the insects $]\left[_{v^{\prime}}\right.$ CAUSE $\left[_{\mathrm{LP}}\right.$ destroyed $\left[_{\mathrm{DP}}\right.$ the crop $\left.\left.\left.]\right]\right]\right]$

The fact that destroy does not allow an intransitive variant is due to the fact that its licensing environment requires embedding under CAUSE while grow is underspecified in this respect. The explanation for the nominalization data in (33) relies on the assumption that Spec,DP is not as semantically loaded as Spec, $v$ p. It is further assumed that by encyclopaedic knowledge destroy always requires external causation while grow refers inherently to an internally caused spontaneous activity, which is optionally facilitated by some agent. Since CAUSE is only implied with destroy but not with grow, only the causer of destroy can be interpreted in a semantically underspecified Spec,DP position. The fact that some verbs like explode behave partly like grow, in allowing the transitive-intransitive alternation, and partly like destroy, in allowing the realization of the causer in nominalizations, is explained by the assumption that the events denoted by such roots can occur spontaneously (internal causation) but can also be directly brought about by some agent (external causation) (cf. also Marantz 1997). In summary, the phenomena in (32) are traced back to syntactic regularities, those in (33) to encyclopaedic, that is, pragmatic conditions.

\subsection{Evaluation}

While some other approaches to argument structure share a number of assumptions with DM - for example, they also operate on category-neutral roots (e.g., Borer 2005; Arad 2002) - of course the radical theses of Distributed Morphology have also drawn some criticism. It has been doubted that all the differences in the syntactic behaviour of verbs can be accounted for with a syntax-free lexicon (cf. e.g., Ramchand 2008).

Cross-linguistic differences might also pose some problems. For example, it is assumed that verbs allowing the unaccusative-transitive alternation are distinguished on the basis of encyclopaedic semantic knowledge from those that do not (Embick 2004: 139). The causative variant of the showcase example grow in (32a) is grammatically licensed and pragmatically acceptable because 
of encyclopaedic knowledge. However, it is not clear why German wachsen 'grow' does not have a causative variant. The alternation would be expected since wachsen does not seem to differ from grow in its encyclopaedic properties. Moreover, many other verbs like to dry 'trocknen' (37) demonstrate that German does not show any kind of structural aversion to alternations of this sort.

(37) a. Der Salat trocknet / wächst.

'The lettuce dries / grows.'

b. Peter trocknet Salat / *wächst Salat.

'Peter dries lettuce / grows lettuce.'

The way the line is drawn between grammatical and pragmatic (un)acceptability also poses some problems. If the use of put with only one argument is considered ungrammatical, then how can similar uses of three-place verbs like German stellen 'put (in upright position)' and geben 'give' be explained (38)?

(38) a. Er gibt. 'He deals (in a card game).'

b. Sie stellt. 'She plays a volleyball such that somebody can smash it.'

Since they are ruled out by grammar, encyclopaedic knowledge cannot save these examples by assigning them an idiomatic meaning. Thus, it might turn out that sometimes argument-structure flexibility is not as general as DM's encyclopaedia suggests, and grammatical restrictions are not as strict as syntax and DM's vocabulary predict.

\section{Outlook}

The overview has shown that stances on lexical decomposition still differ widely, in particular with respect to the questions of where to locate lexical decompositions, how to interpret them, and how to justify them. It has to be noted that most work on lexical decompositions has not been accompanied by extensive empirical research. With the rise of new methods in the domain of corpus analysis, grammaticality judgements, and psycholinguistics (cf. article 7 [Semantics: Foundations, History and Methods] (Engelberg) Lexical decomposition, section 3.6), the empirical basis for further decompositional theories will alter dramatically. It remains to be seen how theories of the sort presented here will cope with the empirical turn in contemporary linguistics. 


\section{References}

Alexiadou, Artemis \& Elena Anagnostopoulou 2004. Voice morphology in the causativeinchoative alternation: Evidence for a non-unified structural analysis of unaccustives. In: A. Alexiadou, E. Anagnostopoulou \& M. Everaert (eds.). The Unaccusativity Puzzle. Explorations of the Syntax-Lexicon Interface. Oxford: Oxford University Press, 114-136. Arad, Maya 2002. Universal features and language-particular morphemes. In: A. Alexiadou (ed.). Theoretical Approaches to Universals. Amsterdam: Benjamins, 15-29.

Bach, Emmon 1968. Nouns and noun phrases. In: E. Bach \& R. T. Harms (eds.). Universals in Linguistic Theory. New York: Holt, Rinehart \& Winston, 90-122.

Barker, Chris 2003. Paraphrase is not enough. Theoretical Linguistics 29, 201-209.

Bartsch, Renate \& Theo Vennemann 1972. Semantic Structures. A Study in the Relation between Semantics and Syntax. Frankfurt/M.: Athenäum.

Bierwisch, Manfred 1982. Formal and lexical semantics. Linguistische Berichte 30, 3-17.

Bierwisch, Manfred 1989. Event nominalizations: Proposals and problems. In: W. Motsch (ed.). Wortstruktur und Satzstruktur. Berlin: Akademie Verlag, 1-73.

Bierwisch, Manfred 1997. Lexical information from a minimalist point of view. In: C. Wilder, H.-M. Gärtner \& M. Bierwisch (eds.). The Role of Economy Principles in Linguistic Theory. Berlin: Akademie Verlag, 227-266.

Bierwisch, Manfred 2002. A case for CAUSE. In: I. Kaufmann \& B. Stiebels (eds.). More than Words: A Festschrift for Dieter Wunderlich. Berlin: Akademie Verlag, 327-353.

Bierwisch, Manfred \& Ewald Lang (eds.) 1989. Dimensional Adjectives. Grammatical Structure and Conceptual Interpretation. Berlin: Springer.

Binnick, Robert I. 1968. On the nature of the 'lexical item'. In: B. J. Darden, C.-J. N. Bailey \& A. Davison (eds.). Papers from the Fourth Regional Meeting of the Chicago Linguistic Society $(=C L S)$. Chicago, IL: Chicago Linguistic Society, 1-13.

Binnick, Robert J. 1972. Zur Entwicklung der generativen Semantik. In: W. Abraham \& R. J. Binnick (eds.). Generative Semantik. Frankfurt/M.: Athenäum, 1-48.

Borer, Hagit 2005. Structuring Sense, vol. 2: The Normal Course of Events. Oxford: Oxford University Press.

Carter, Richard J. 1976. Some constraints on possible words. Semantikos 1, 27-66.

Carter, Richard 1988. Arguing for semantic representations. In: B. Levin \& C. Tenny (eds.). On Linking: Papers by Richard Carter. Lexicon Project Working Papers 25. Cambridge, MA: Center for Cognitive Science, MIT, 139-166.

Chomsky, Noam 1965. Aspects of the Theory of Syntax. Cambridge, MA: The MIT Press.

Chomsky, Noam 1970. Some empirical issues in the theory of transformational grammar. In: P. S. Peters (ed.). Goals of Linguistic Theory. Englewood Cliffs, NJ: Prentice Hall, 63-130.

Croft, William 1998. Event structure in argument linking. In: M. Butt \& W. Geuder (eds.). The Projection of Arguments: Lexical Compositional Factors. Stanford, CA: CSLI Publications, 21-63.

Culicover, Peter W. \& Ray Jackendoff 2005. Simpler Syntax. Oxford: Oxford University Press. Davidson, Donald 1967. The logical form of action sentences. In: N. Rescher (ed.). The Logic of Decision and Action. Pittsburgh, PA: University of Pittsburgh Press, 81-95.

Dowty, David R. 1972. Studies in the Logic of Verb Aspect and Time Reference in English. Ph.D. dissertation. University of Texas, Austin, TX.

Dowty, David R. 1976. Montague Grammar and the lexical decomposition of causative verbs. In: B. Partee (ed.). Montague Grammar. New York: Academic Press, 201-246. 
Dowty, David R. 1979. Word Meaning and Montague Grammar. The Semantics of Verbs and Times in Generative Semantics and in Montague's PTQ. Dordrecht: Reidel.

Dowty, David R. 1991. Thematic proto-roles and argument selection. Language 67, 547-619.

Durst, Uwe 2003. The Natural Semantic Metalanguage approach to linguistic meaning. Theoretical Linguistics 29, 157-200.

Embick, David 2004. Unaccusative syntax and verbal alternations. In: A. Alexiadou, E. Anagnostopoulou \& M. Everaert (eds.). The Unaccusativity Puzzle. Explorations of the SyntaxLexicon Interface. Oxford: Oxford University Press, 137-158.

Embick, David \& Rolf Noyer 2007. Distributed Morphology and the syntax/morphology interface. In: G. Ramchand \& C. Reiss (eds.). The Oxford Handbook of Linguistic Interfaces. Oxford: Oxford University Press, 289-324.

Engelberg, Stefan 2006. A theory of lexical event structures and its cognitive motivation. In: D. Wunderlich (ed.). Advances in the Theory of the Lexicon. Berlin: de Gruyter, 235-285.

Erteschik-Shir, Nomi \& Tova Rapoport 2005. Path predicates. In: N. Erteschik-Shir \& T. Rapoport (eds.). The Syntax of Aspect. Deriving Thematic and Aspectual Interpretation. Oxford: Oxford University Press, 65-86.

Erteschik-Shir, Nomi \& Tova Rapoport 2007. Projecting argument structure. The grammar of hitting and breaking revisited. In: E. Reuland, T. Bhattacharya \& G. Spathas (eds.). Argument Structure. Amsterdam: Benjamins, 17-35.

Fillmore, Charles J. 1968a. Lexical entries for verbs. Foundations of Language 4, 373-393.

Fillmore, Charles J. 1968b. The case for case. In: E. Bach \& R. T. Harms (eds.). Universals in Linguistic Theory. New York: Holt, Rinehart \& Winston, 1-88.

Fodor, Jerry A. 1970. Three reasons for not deriving 'kill' from 'cause to die'. Linguistic Inquiry 1, 429-438.

Fodor, Jerry A., Merrill F. Garrett, Edword C. T. Walker \& Cornelia H. Parkes 1980. Against definitions. Cognition 8, 263-367.

Fodor, Jerry \& A. \& Ernie Lepore 1999. Impossible words? Linguistic Inquiry 30, 445-453.

Gamerschlag, Thomas 2005. Komposition und Argumentstruktur komplexer Verben. Eine lexikalische Analyse von Verb-Verb-Komposita und Serialverbkonstruktionen. Berlin: Akademie Verlag.

Geurts, Bart 2003. Semantics as lexicography. Theoretical Linguistics 29, 223-226.

Goddard, Cliff 1998. Semantic Analysis. A Practical Introduction. Oxford: Oxford University Press.

Goddard, Cliff 2002a. Lexical decomposition II: Conceptual axiology. In: A. D. Cruse et al. (eds.). Lexikologie - Lexicology. Ein internationales Handbuch zur Natur und Struktur von Wörtern und Wortschätzen - An International Handbook on the Nature and Structure of Words and Vocabularies, (HSK 21.1). Berlin: de Gruyter, 256-268.

Goddard, Cliff 2002b. The search for the shared semantic core of all languages. In: C. Goddard \& A. Wierzbicka (eds.). Meaning and Universal Grammar, vol. 1: Theory and Empirical Finding. Amsterdam: Benjamins, 5-40.

Goddard, Cliff 2006. Ethnopragmatics: A new paradigm. In: C. Goddard (ed.). Ethnopragmatics. Understanding Discourse in Cultural Context. Berlin: de Guyter, 1-30.

Goddard, Cliff 2008a. Natural Semantic Metalanguage: The state of the art. In: C. Goddard (ed.). Cross-Linguistic Semantics. Amsterdam: Benjamins, 1-34.

Goddard, Cliff 2008b. Towards a systematic table of semantic elements. In: C. Goddard (ed.). Cross-Linguistic Semantics. Amsterdam: Benjamins, 59-81. 
Goddard, Cliff, \& Anna Wierzbicka (eds.) 1994a. Semantic and Lexical Universals - Theory and Empirical Findings. Amsterdam: Benjamins.

Goddard, Cliff \& Anna Wierzbicka 1994b. Introducing lexical primitives. In: C. Goddard \& A. Wierzbicka (eds.). Semantic and Lexical Universals - Theory and Empirical Findings. Amsterdam: Benjamins, 31-54.

Goddard, Cliff \& Anna Wierzbicka 2002. Semantic primes and universal grammar. In:

C. Goddard \& A. Wierzbicka (eds.). Meaning and Universal Grammar, vol. 1: Theory and Empirical Findings. Amsterdam: Benjamins, 41-85.

Grimshaw, Jane 1990. Argument Structure. Cambridge, MA: The MIT Press.

Gruber, Jeffrey S. 1965. Studies in Lexical Relations. Ph.D. dissertation. MIT, Cambridge, MA. Guerssel, Mohamed, Kenneth Hale, Mary Laughren, Beth Levin \& Josie White Eagle 1985.

A cross-linguistic study of transitivity alternations. In: W. H. Eilfort, P. D. Kroeber \&

K. L. Peterson (eds.). Papers from the Parasession on Causatives and Agentivity at the 21st

Regional Meeting of the Chicago Linguistic Society (= CLS), April 1985. Chicago, IL: Chicago Linguistic Society, 48-63.

Hale, Ken \& Samuel Jay Keyser 1987. A View from the Middle. Lexicon Project Working Papers 10. Cambridge, MA: Center for Cognitive Science, MIT.

Hale, Ken \& Samuel Jay Keyser 1993. On argument structure and the syntactic expression of lexical relations. In: K. Hale \& S. J. Keyser (eds.). The View from Building 20. Essays in Linguistics in Honor of Sylvain Bromberger. Cambridge, MA: The MIT Press, 53-109.

Hale, Ken \& Samuel Jay Keyser 1997. On the complex nature of simple predicators. In: A. Alsina, J. Bresnan \& P. Sells (eds.). Complex Predicates. Stanford, CA: CSLI Publications, 29-65.

Hale, Ken \& Samuel Jay Keyser 1999. A response to Fodor and Lepore, "Impossible words?" Linguistic Inquiry 30, 453-466.

Hale, Ken \& Samuel Jay Keyser 2002. Prolegomenon to a Theory of Argument Structure. Cambridge, MA: The MIT Press.

Hale, Ken \& Samuel Jay Keyser 2005. Aspect and the syntax of argument structure. In: N. Erteschik-Shir \& T. Rapoport (eds.). The Syntax of Aspect. Deriving Thematic and Aspectual Interpretation. Oxford: Oxford University Press, 11-41.

Halle, Morris \& Alec Marantz 1993. Distributed Morphology and the pieces of inflection. In: K. Hale \& S. J. Keyser (eds.). The View from Building 20. Essays in Honor of Sylvain Bomberger. Cambridge, MA: The MIT Press, 111-176.

Harley, Heidi 2002. Possession and the double object construction. In: P. Pica \& J. Rooryck (eds.). Linguistic Variation Yearbook, vol. 2. Amsterdam: Benjamins, 31-70.

Harley, Heidi \& Rolf Noyer 1999. Distributed Morphology. GLOT International 4, 3-9.

Harley, Heidi \& Rolf Noyer 2000. Formal versus encyclopedic properties of vocabulary: Evidence from nominalizations. In: B. Peeters (ed.). The Lexicon-Encyclopedia Interface. Amsterdam: Elsevier, 349-375.

Immler, Manfred 1974. Generative Syntax - Generative Semantik. München: Fink. Jackendoff, Ray 1972. Semantic Interpretation in Generative Grammar. Cambridge, MA: The MIT Press.

Jackendoff, Ray 1976. Toward an explanatory semantic representation. Linguistic Inquiry 7, 89-150.

Jackendoff, Ray 1983. Semantics and Cognition. Cambridge, MA: The MIT Press.

Jackendoff, Ray 1987. Relations in linguistic theory. Linguistic Inquiry 18, 369-411.

Jackendoff, Ray 1990. Semantic Structures. Cambridge, MA: The MIT Press. 
Jackendoff, Ray 2002. Foundations of Language. Brain, Meaning, Grammar, Evolution. Oxford: Oxford University Press.

Joppen, Sandra \& Dieter Wunderlich 1995. Argument linking in Basque. Lingua 97, 123-169.

Joshi, Aravind 1974. Factorization of verbs. In: C. H. Heidrich (ed.). Semantics and Communication. Amsterdam: North-Holland, 251-283.

Kandiah, Thiru 1968. Transformational Grammar and the layering of structure in Tamil. Journal of Linguistics 4, 217-254.

Kaufmann, Ingrid 1995a. Konzeptuelle Grundlagen semantischer Dekompositionsstrukturen. Die Kombinatorik lokaler Verben und prädikativer Komplemente. Tübingen: Niemeyer.

Kaufmann, Ingrid 1995b. O- and D-predicates: A semantic approach to the unaccusativeunergative distinction. Journal of Semantics 12, 377-427.

Kaufmann, Ingrid 1995c. What is an (im-)possible verb? Restrictions on semantic form and their consequences for argument structure. Folia Linguistica 29, 67-103.

Kiparsky, Paul 1997. Remarks on denominal verbs. In: A. Alsina, J. Bresnan \& P. Sells (eds.). Complex Predicates. Stanford, CA: CSLI Publications, 473-499.

Lakoff, George 1965. Irregularity in Syntax. Ph.D. dissertation. Indiana University, Bloomington, IN. Reprinted: New York: Holt, Rinehart \& Winston, 1970.

Lakoff, George \& John Robert Ross 1972. A note on anaphoric islands and causatives. Linguistic Inquiry 3, 121-125.

Larson, Richard K. 1988. On the double object construction. Linguistic Inquiry 19, 335-391.

Levin, Beth 1985. Lexical semantics in review: An introduction. In: B. Levin (ed.). Lexical Semantics in Review. Cambridge, MA: The MIT Press, 1-62.

Levin, Beth 1993. English Verb Classes and Alternations. A Preliminary Investigation. Chicago, IL: The University of Chicago Press.

Levin, Beth 1995. Approaches to lexical semantic representation. In: D. E. Walker, A. Zampolli \& N. Calzolari (eds.). Automating the Lexicon: Research and Practice in a Multilingual Environment. Oxford: Oxford University Press, 53-91.

Levin, Beth \& Malka Rappaport Hovav 2005. Argument Realization. Cambridge: Cambridge University Press.

Lewis, David 1973. Causation. The Journal of Philosophy 70, 556-567.

Maienborn, Claudia 2003. Event-internal modifiers: Semantic underspecification and conceptual interpretation. In: E. Lang, C. Maienborn \& C. Fabricius-Hansen (eds.). Modifying Adjuncts. Berlin: Mouton de Gruyter, 475-509.

Marantz, Alec 1997. No escape from syntax: Don't try morphological analysis in the privacy of your own lexicon. In: A. Dimitriadis, L. Siegel, C. Surek-Clark \& A. Williams (eds.). Proceedings of the 21st Annual Penn Linguistics Colloquium. Philadelphia, PA: University of Pennsylvania Press, 201-225.

Mateu, Jaume 2001. Unselected objects. In: N. Dehé \& A. Wanner (eds.). Structural Aspects of Semantically Complex Verbs. Frankfurt/M.: Lang, 83-104.

Matthewson, Lisa 2003. Is the meta-language really natural? Theoretical Linguistics 29, 263-274.

McCawley, James D. 1968. Lexical insertion in a Transformational Grammar without deep structure. In: B. J. Darden, C.-J. N. Bailey \& A. Davison (eds.). Papers from the Fourth Regional Meeting of the Chicago Linguistic Society. Chicago, IL: Chicago Linguistics Society, 71-80.

McCawley, James D. 1971. Prelexical syntax. In: R. J. O’Brien (ed.). Report of the 22nd Annual Round Table Meeting on Linguistics and Language Studies. Washington, DC: Georgetown University Press, 19-33. 
McCawley, James D. 1994. Generative Semantics. In: R. E. Asher \& J. M. Y. Simpson (ed.). The

Encyclopedia of Language and Linguistics. Oxford: Pergamon, 1398-1403.

Montague, Richard 1973. The proper treatment of quantification in ordinary English. In:

J. Hintikka, J. M. E. Moravcsik \& P. Suppes (eds.). Approaches to Natural Language.

Proceedings of the 1970 Stanford Workshop on Grammar and Semantics. Dordrecht:

Reidel, 221-242.

Morgan, Jerry L. 1969. On arguing about semantics. Papers in Linguistics 1, 49-70.

Postal, Paul M. 1971. On the surface verb 'remind'. In: C. J. Fillmore \& D. T. Langendoen (eds.).

Studies in Linguistic Semantics. New York: Holt, Rinehart \& Winston, 180-270.

Pustejovsky, James 1988. The geometry of events. In: C. Tenny (ed.). Studies in Generative

Approaches to Aspect. Cambridge, MA: The MIT Press, 19-39.

Pustejovsky, James 1991a. The syntax of event structure. Cognition 41, 47-81.

Pustejovsky, James 1991b. The generative lexicon. Computational Linguistics 17, 409-441.

Pustejovsky, James 1995. The Generative Lexicon. Cambridge, MA: The MIT Press.

Pustejovsky, James \& Pierrette Bouillon 1995. Aspectual coercion and logical polysemy. Journal of Semantics 12, 133-162.

Ramchand, Gillian C. 2008. Verb Meaning and the Lexicon. A First-Phase Syntax. Cambridge:

Cambridge University Press.

Rappaport, Malka 1985. Review of Joshi’s “Factorization of verbs”. In: B. Levin (ed.). Lexical

Semantics in Review. Cambridge, MA: The MIT Press, 137-148.

Rappaport, Malka, Mary Laughren \& Beth Levin 1987. Levels of Lexical Representation. Lexicon

Project Working Papers 20. Cambridge, MA: MIT.

Rappaport, Malka \& Beth Levin 1988. What to do with $\theta$-roles. In: W. Wilkins (ed.). Syntax and

Semantics 21: Thematic Relations. New York: Academic Press, 7-36.

Rappaport, Malka, Beth Levin \& Mary Laughren 1993. Levels of lexical representation. In:

J. Pustejovsky (ed.). Semantics and the Lexicon. Dordrecht: Kluwer, 37-54.

Rappaport Hovav, Malka \& Beth Levin 1998. Building verb meanings. In: M. Butt \& W. Geuder

(eds.). The Projection of Arguments: Lexical Compositional Factors. Stanford, CA: CSLI

Publications, 97-134.

Rappaport Hovav, Malka \& Beth Levin 2005. Change-of-state verbs: Implications for theories

of argument projection. In: N. Erteschik-Shir \& T. Rapoport (eds.). The Syntax of Aspect.

Deriving Thematic and Aspectual Interpretation. Oxford: Oxford University Press, 274-286.

Reinhart, Tanya 2002. The theta system - an overview. Theoretical Linguistics 28, 229-290.

Riemer, Nick 2006. Reductive paraphrase and meaning: A critique of Wierzbickian semantics.

Linguistics \& Philosophy 29, 347-379.

Ritter, Elizabeth \& Sara Thomas Rosen 1998. Delimiting events in syntax. In: M. Butt \& W.

Geuder (eds.). The Projection of Arguments: Lexical Compositional Factors. Stanford, CA:

CSLI Publications, 135-164.

Ross, John Robert 1972. Act. In: D. Davidson \& G. Harman (eds.). Semantics of Natural Language. Dordrecht: Reidel, 70-126.

Rozwadowska, Bozena 1988. Thematic restrictions on derived nominals. In: W. Wilkins (ed.).

Syntax and Semantics 21: Thematic Relations. New York: Academic Press, 147-165.

Ruppenhofer, Josef, Michael Ellsworth, Miriam R. L. Petruck, Christopher R. Johnson \& Jan

Scheffczyk 2006. Frame Net II: Extended Theory and Practice, http://framenet.icsi.

berkeley.edu/index.php?option=com_wrapper\&Itemid=126. December 30, 2006.

Shibatani, Masayoshi 1976. The grammar of causative constructions: A conspectus. In: M.

Shibatani (ed.). The Grammar of Causative Constructions. New York: Academic Press, 1-40. 
Stiebels, Barbara 1996. Lexikalische Argumente und Adjunkte. Zum semantischen Beitrag von verbalen Präfixen und Partikeln. Berlin: Akademie Verlag.

Stiebels, Barbara 1998. Complex denominal verbs in German and the morphology-semantics interface. In: G. Booij \& J. van Marle (eds.). Yearbook of Morphology 1997. Dordrecht: Kluwer, 265-302.

Stiebels, Barbara 2002. Typologie des Argumentlinkings. Ökonomie und Expressivität. Berlin: Akademie Verlag.

Stiebels, Barbara 2006. From rags to riches. Nominal linking in contrast to verbal linking. In: D. Wunderlich (ed.). Advances in the Theory of the Lexicon. Berlin: de Gruyter, 167-234.

Summers, Della (Med.) 1995. Longman Dictionary of Contemporary English. München: Langenscheidt-Longman.

Taylor, John R. 2000. The network model and the two-level model in comparison. In: B. Peeters (ed.). The Lexicon-Encyclopedia Interface. Amsterdam: Elsevier, 115-141.

Tenny, Carol 1987. Grammaticalizing Aspect and Affectedness. Ph.D. dissertation. MIT, Cambridge, MA.

Tenny, Carol 1988. The aspectual interface hypothesis: The connection between syntax and lexical semantics. In: C. Tenny (ed.). Studies in Generative Approaches to Aspect. Cambridge, MA: The MIT Press, 1-18.

Travis, Lisa 2000. Event structure in syntax. In: C. Tenny (ed.). Events as Grammatical Objects. The Converging Perspectives of Lexical Semantics and Syntax. Stanford, CA: CSLI Publications, 145-185.

van Valin, Robert D. Jr. 1993. A synopsis of Role and Reference Grammar. In: R. D. van Valin (ed.). Advances in Role and Reference Grammar. Amsterdam: Benjamins, 1-164.

Vendler, Zeno 1957. Verbs and times. The Philosophical Review LXVI, 143-160.

van Voorst, Jan 1988. Event Structure. Amsterdam: Benjamins.

Wierzbicka, Anna 1972. Semantic Primitives. Frankfurt/M.: Athenäum.

Wierzbicka, Anna 1980. Lingua Mentalis. The Semantics of Natural Language. Sydney: Academic Press.

Wierzbicka, Anna 1985. Lexicography and Conceptual Analysis. Ann Arbor, MI: Karoma.

Wierzbicka, Anna 1987. English Speech Act Verbs. A Semantic Dictionary. Sydney: Academic Press.

Wierzbicka, Anna 1988. The Semantics of Grammar. Amsterdam: Benjamins.

Wierzbicka, Anna 1992. Semantics, Culture, and Cognition. Universal Human Concepts in Culture-Specific Configurations. Oxford: Oxford University Press.

Wierzbicka, Anna 1996. Semantics. Primes and Universals. Oxford: Oxford University Press.

Wierzbicka, Anna 1999. Emotions across Languages and Cultures. Cambridge: Cambridge University Press.

Wierzbicka, Anna 2009. The theory of the mental lexicon. In: S. Kempgen et al. (eds.). Die slavischen Sprachen - The Slavic Languages. Ein internationales Handbuch zu ihrer Geschichte, ihrer Struktur und ihrer Erforschung - An International Handbook of their History, their Structure and their Investigation. (HSK 32.1). Berlin: de Gruyter, 848-863.

von Wright, George Henrik 1963. Norm and Action. London: Routledge \& Kegan Paul.

Wunderlich, Dieter 1991. How do prepositional phrases fit into compositional syntax and semantics? Linguistics 25, 283-331.

Wunderlich, Dieter 1994. Towards a lexicon-based theory of agreement. Theoretical Linguistics 20, 1-35. 
Wunderlich, Dieter 1996. Models of lexical decomposition. In: E. Weigand \& F. Hundsnurscher (eds.). Lexical Structures and Language Use. Proceedings of the International Conference on Lexicology and Lexical Semantics, Münster, September 13-15, 1994. Vol. 1: Plenary Lectures and Session Papers. Tübingen: Niemeyer, 169-183.

Wunderlich, Dieter 1997a. CAUSE and the structure of verbs. Linguistic Inquiry 28, 27-68.

Wunderlich, Dieter 1997b. Argument extension by lexical adjunction. Journal of Semantics 14 , 95-142.

Wunderlich, Dieter 2000. Predicate composition and argument extension as general options - a study in the interface of semantic and conceptual structure. In: B. Stiebels \& D. Wunderlich (eds.). Lexicon in Focus. Berlin: Akademie Verlag, 247-270.

Wunderlich, Dieter 2006. Towards a structural typology of verb classes. In: D. Wunderlich (ed.). Advances in the Theory of the Lexicon. Berlin: de Gruyter, 57-166.

Zubizarreta, Maria Luisa \& Eunjeong Oh 2007. On the Syntactic Composition of Manner and Motion. Cambridge, MA: The MIT Press. 